\title{
“2D or Not 2D”: Shape-Programming Polymer Sheets
}

\author{
Ying Liu, Jan Genzer*, Michael D. Dickey ${ }^{*}$ \\ Department of Chemical and Biomolecular Engineering \\ North Carolina State University \\ Raleigh, NC 27695-7905 \\ USA
}

\begin{abstract}
This review summarizes progress toward programming two-dimensional (2D) polymer sheets which respond to a variety of external stimuli to form three-dimensional (3D) shapes or macroscopically planar sheets comprising topographical features. Shape programming strategically adds value or function to $2 \mathrm{D}$ sheets, films, or coatings that can be created inexpensively. 2D substrates are common form factors that are compatible with ordinary 2D patterning techniques (i.e., inkjet, photolithography, roll-to-roll printing) and may be stored, packed, and shipped efficiently. Polymer materials are attractive due to their flexibility, light weight, low price, and compatibility with high throughput processing. This review highlights strategies for triggering shape change in planar polymeric materials. The strategies are divided into four broad categories: 1) 2D substrates with latent topography "programmed" using conventional microfabrication, 2) 2D substrates that form topography due to imposed or selfgenerated stress, 3) 2D substrates form 3D shapes by out-of-plane bending, and 4) 2D substrates that use "hinges" to achieve out-of-plane folding. The review highlights all strategies while focusing primarily on last two approaches.
\end{abstract}

\section{Keywords}

Shape programming, Active materials, Folding, Polymer sheets.

*Corresponding Authors: jgenzer@ncsu.edu Tel: +1 (919) 515-2069, mddickey@ncsu.edu Tel: +1 (919) 513-0273, 


\section{Table of Contents}

1. Introduction

1.1 Overview

1.2 Why is shape programming from $2 \mathrm{D}$ to $3 \mathrm{D}$ interesting?

2. Strategies for transforming $2 \mathrm{D}$ planes to $3 \mathrm{D}$ shapes

2.1 Conventional fabrication (Strategy 1).

2.2 Induced surface topographies (Strategy 2)

2.3 Bending (Strategy 3).

2.4 Folding (Strategy 4)

2.5 Discussion for out-of-plane shape programming (Strategies 3 and 4)

2.6 Applications for out-of-plane shape programming (Strategies 3 and 4)

3. Conclusion, opportunities, and challenges for shape programming

Acknowledgements

References 


\section{Introduction}

\subsection{Overview}

This review focuses on strategies for shape-programming polymeric materials that can convert planar two-dimensional (2D) polymer sheets to three-dimensional (3D) shapes. Shape-programming changes the physical geometry of materials in response to an external stimulus. The desire to create $3 \mathrm{D}$ shapes is stimulated by the premise that shape defines function of most materials. Employing 2D planar sheets to fabricate 3D shapes brings several technological advantages and appeals: 1) 2D polymer sheets and coatings can be mass-produced inexpensively using high-throughput processing methods and find use in our daily lives including the substrates for printed electronics, laminate coatings, and plastic films; 2) 2D polymer sheets are compatible with most planar processes developed for the semiconductor industry as well as other patterning techniques, such as, screen printing, roll-to-roll processing, gravure printing, and inkjet printing; 3) planar sheets can be stacked efficiently for storage, transport, or remote deployment.

We divide shape-programming of 2D materials into four broad categories as illustrated in Figure 1: 1) 2D substrates that use additive or subtractive processes, such as lithography, to create topography; 2) 2D substrates that form topography, e.g., wrinkles or creases, on their surface in response to an external stimulus; 3) 2D substrates that can form out-of-plane 3D shapes by bending, and 4) 2D substrates that use "hinges" to achieve out-of-plane folding. Unlike shape transformation, which describes the immediate alteration of the shape due to mechanical processing, shape programming involves a processing step (or a design strategy) to change shape rationally and controllably at a desired time and defined location in response to an external stimulus. It could be argued that Strategy 1 does not involve true shape programming steps since the shape change happens during processing and not in response to a subsequent external stimulus. However, we include it here for completeness and because it can be used to create latent shape change.

\section{Figure 1}


The importance of shape programming in planar materials unifies the four strategies depicted in Figure 1 and points to some similarities among them. For example, while samples prepared by strategies 1 and 2 result in macroscopically planar substrates that support microscopic (typically sub-millimeter) surface topography, strategies 3 and 4 describe the formation of 3D out-of-plane shapes by bending, folding, or rolling to produce dramatic macroscopic shape changes as well as microscopic ones, often in a facile manner. Shape programming characterized by strategies 3 and 4 can occur due to asymmetrical distortion of the material, expansion (e.g., thermal expansion, swelling), contraction (e.g., strain relaxation, de-swelling), or flow or deformation (e.g., displacement of material due to a stress).

Figure 2 differentiates the subtle differences between 'bending' (strategy 3) and 'folding' (strategy 4). These terms are sometimes used interchangeably since there is not a universally agreed upon definition that differentiates them. Several recent publications discuss the difference between bending and folding in shape programming materials.[15] Simply stated, folding involves localized deformation whereas bending is global. Lauff et. al provide a thorough summary of the literature on this topic and define bending as the "distributed deformation of a material along the deflected area that creates curvature" (i.e., distributed curvature) and folding as the "localized deformation of a material along crease patterns to create new shapes" (i.e., localized curvature along a crease). [1,2] Figure 2a shows a clear case of folding (where the ratio of red to blue approaches zero) and Figure 2d shows a clear case of bending (where the ratio of blue to red approaches zero). Figures $\mathbf{2 b}$ and $2 \mathbf{c}$ illustrate why it is difficult to definitively distinguish bending from folding. Figure 2e demonstrates that a series of local folds can lead to global bending.

\section{Figure 2}

Other excellent reviews cover aspects of shape programming by focusing on common materials (e.g., hydrogels, elastomers) or highlighting adaptive composites. $[2,4,6-16]$ In this review we provide a general roadmap for different strategies and materials used in shape programming. Specifically, we concentrate only on polymeric materials with an occasional mention of other materials that might be utilized in 
conjunction with polymers for shape programming. Polymeric materials are attractive for shape programming due to their flexibility, light weight, low price, and compatibility with high throughput processing. We also focus primarily on Strategy 3 and 4; that is, conversion of 2D planar polymer sheets to out-of-plane structures by bending and folding. We limit our discussion of strategies 1 and 2 to a brief review with highlights of previously published reviews and references on these topics.

\subsection{Why is shape programming from 2D to 3D interesting?}

2D polymeric substrates may be manufactured industrially using low-cost, highthroughput processes, including, melt extrusion, injection molding,vacuum forming, pultrusion, or transfer molding [17,18]. In general, 2D substrates are compatible with many inexpensive 2D patterning techniques (e.g., lithography, screen printing, inkjet printing, gravure printing, roll-to-roll processing, and laser cutting) and more sophisticated microfabrication and nanofabrication techniques (e.g., spin casting, photolithography, thin film deposition, etching, and other additive/subtractive processes including unconventional patterning techniques such as dip pen lithography, colloidal lithography, imprint lithography, and directed self-assembly) [19].

Converting 2D sheets to 3D structures may be beneficial for a variety of purposes. Examples include, but are not limited to: 1) changing the shape of a polymer sheet to achieve a final product (e.g., packaging); 2) assembling structures (e.g., electronics or optics) that are fabricated in 2D to achieve final desired 3D shape; 3) reconfiguring the shape, and thus, function of a substrate for applications that are both low-tech (e.g., responsive toys for children) and high-tech (e.g., shape reconfigurable devices or nonfouling surfaces); [20-24] 4) deploying materials conveniently and compactly in a flat 2D form and have a 3D shape assemble at the destination site; 5) tuning the properties of a surface (e.g., wetting or optical properties) that depend strongly on surface topography; and 6) implanting a structure in a compact form factor and have it assemble in situ (e.g., a boat in a bottle, or an implantable device). [25-27]

There are many compelling applications of $2 \mathrm{D}$ to $3 \mathrm{D}$ transformations that have been proposed and demonstrated. For example, sensors constructed in 3D space allow for the measurement of signals from three independent axes to obtain accurate angular 
and orientation parameters.[22] Morphing structures such as "Morphees" (i.e., shapeshifting mobile devices) and "MorePhone" (i.e., a cellphone curls upon a call) have been proposed for next-generation mobile devices. [28] In addition, shape programming from has also been applied in smart adhesives, [29] anti-fouling coatings, [30,31] sensors. $[32,33]$

\section{Strategies for transforming 2D planes to 3D shapes}

Many materials strategies and stimuli can be utilized for shape programming polymers. Following the scheme in Figure 1, we first overview those four strategies to convert 2D planes to 3D shapes and then narrow our focus to strategies 3 and 4.

\subsection{Conventional fabrication (Strategy 1)}

Additive or subtractive microfabrication can generate topography on 2D substrates.[19] Of the four strategies introduced in Figure 1, this approach is the most commonly used because of its importance for the mass production of electronics and computer chips. It could be argued that these techniques are not truly shape programming because the shape change usually takes place during processing, and not at some later time programmed into the material. However, conventional photolithography may be considered a shape programming method since the latent topography can be revealed only upon exposure to a liquid developer which may be thought of as "an external stimulus".

Figure 3 illustrates the two general types of conventional lithographic methods, which expose polymeric films (e.g., photoresists) to photons (e.g., UV light, X-ray) or particles (e.g., electrons and ions) to form relief structures in the film. Chemical changes in the films alter the solubility of the polymer in a liquid developer relative to the unexposed regions.[34,35] Positive photoresists become more soluble in a developer solution after exposure to the incident beam, while negative photoresists become less soluble after exposure. The most common lithographic method utilizes a mask to transmit patterns of photons onto selected regions on the substrate. Alternatively, a focused beam of photons or electrons may be rastered across a substrate, but these serial

processes generally cannot achieve the high throughput patterning realized using a mask. Lithographic methods are dominant technologies in the fabrication of 
microelectromechanical systems (MEMS), optics, and computer chips. These processes are inherently 2D and thus are poorly suited for patterning curved and out of plane surfaces. However, features created by lithography may be patterned on a 2D surface and then assembled into 3D shapes by, for example, bending or folding (discussed later in this review).[36-38]

\section{Figure 3}

In addition to conventional lithographic methods, there are many additive techniques (e.g., sputtering and evaporation $[39,40]$ ) or subtractive methods (e.g., etching, machining process $[41,42])$ for defining topography on a surface.

There are also numerous "unconventional" lithographic approaches for introducing surface topography on 2D substrates. [34,43,44] Examples include imprint lithography,[45-49] directed self-assembly,[50] dip pen lithography,[51] direct-write lithography, [52] colloidal lithography,[53,54], or soft lithography. [55,56] Selfassembly processes (e.g., crystallization, phase separation, order-to-order transition, colloidal assembly) can also be employed to alter surface topography spontaneously by interaction-driven association of individual (often disordered) building blocks into organized arrays.[34,57-59] There are also numerous low-cost, low-resolution patterning techniques, including, inkjet printing, screen printing, and roll-to-roll patterning. In addition, 3D shapes can be realized by, for example, stereolithography [60-64] or inkbased direct-write methods [65-68]. The examples given here are by no means comprehensive and are only given to suggest the wide range of patterning techniques available. The reader is referred to several monographs and references on unconventional fabrication and printed electronics[69-73].

In summary, most of these techniques are "shape transforming" rather than "shape programming" because the topography change occurs directly during the patterning processes themselves rather than in response to an external stimulus. For this reason, these conventional microfabrication methods will not be discussed in more detail in this review despite their prevalence industrially and in laboratory environments. 


\subsection{Induced surface topographies (Strategy 2)}

There are many strategies to induce surface topography onto smooth $2 \mathrm{D}$ substrates. Unlike materials addition or subtraction (Strategy 1), the surface topographies discussed here form due to the inherent properties designed into the substrates.

Wrinkling (or "buckling") is a prominent mechanism to form tunable periodic sinusoidal surface topography, which has been reviewed in detail previously. [6,74-80] Buckles typically form due to compressive forces acting on a thin rigid film attached to a soft substrate (Figure 4a). Elastomers are usually used as the substrate. PDMS is employed often for these applications due to its outstanding flexibility and ability to be stretched $[74,81]$. Other materials, such as viscoelastic polymers (e.g., polystyrene), hydrogels and polymer brushes can also be used to form buckles.[82-86] The stress may be imposed externally (e.g., thermal expansion or mechanical strain) or by chemical modification of the surface of the polymeric substrate. For example, the bottom substrate may be heated and expanded uniformly either by an external heat source before the deposition of the top film or by thermal energy generated during the deposition. Upon cooling, compressive stress develops in the top metal film, which competes with the tensile stress in the bottom substrate and results in the formation of randomly oriented wrinkles (isotropic wrinkles).[82,87-89] Wrinkles can also form on a mechanically prestretched polymer sheets with a rigid top film (e.g., metal, oxide or oxidized original surface with high degree of crosslinks) when introducing or releasing mechanical strain.[80,90,91] Imposing larger pre-strains $(>10 \%)$ results in topography comprising hierarchically-structured wrinkles, in which smaller wrinkles reside on top of larger ones.

(Figure 4b). Wrinkles can also be induced by swelling bilayer structures or by employing gradients in crosslink density. These techniques are applied commonly in hydrogel systems.[76,78,86,92-95] In addition, wrinkles can occur due to the surface modification (e.g., oxidation) of an elastomer during sputter deposition. The oxidation creates a stiff layer on the surface of the elastomer and the mismatch between the mechanical properties of such skin and the base material generates a compressive stress during strain release that induces buckling.[96] The resulting buckles possess characteristic wavelength that depends on the mechanical properties and geometry of the system. The in-plane organization of the wrinkles depends on the direction of the 
imposed strain, as illustrated in Figure 4c.[76] During the past several decades various models have been developed to study the mechanism for wrinkle formation.[80,82,97102] The geometry and size of wrinkles (including the wavelength, amplitude) has been found to depend on the thickness of the top film and the foundation as well as the materials properties (e.g., Young's modulus, Poisson's ratio) of the two layers and applied strain.

\section{Figure 4}

The ability to form wrinkled/buckled surfaces has been used in various applications, including, anti-fouling coatings,[31,103] microfluidic devices to direct the cell growth,[104] "smart" adhesive surfaces,[105] optical devices such as microlenses [106] and diffraction gratings.[87,107] By making use of the buckling mechanism, buckled structures can be applied as a characterization tool to assess the modulus of materials employed as rigid thin layers.[75,77,107,108] The application of buckled structures in light trapping materials has also been explored.[109-112] Hierarchical buckles are well-suited topographical structures that enhance trapping of light with various wavelengths since the buckle wavelengths range from micro- to nano-scale.[81]

Besides wrinkling (continuous undulations on the surface), other thin-film instabilities can form in response to stress, including, craters, creases, folds, localized ridges, or delamination (non-continuous deep folds on the surface). The type of topography depends on the degree of adhesion and difference in modulus between the film and the substrate. These instabilities form self-organized topographies such as wrinkles, creases, and buckles in response to a stimulus (Figure 5).[90,113-121] The use of electric fields to induce film instabilities is another means of generating functional surfaces and on-demand creases or folds.[113,114]

\section{Figure 5}

Dewetting instabilities of polymer thin films (thickness $\sim 100 \mathrm{~nm}$ ) offer a low-cost and lithographic free approach for patterning surfaces with tailored topographies. Molecular interactions (e.g., van der Waals interactions, residual stresses due to long chain entanglement) or surface heterogeneities drive the spontaneous rupture of these thin 
films (e.g., spinodal dewetting). (Figure 6a,b) [122-130] Desired patterns can be generated by tuning physical or chemical heterogeneity on the substrate.[122,123] Surface patterns created by rational dewetting have been applied for optoelectronics and semiconductor devices. [122-124]

\section{Figure 6}

Dewetting of thicker films (thickness $>100 \mathrm{~nm}$ ) can be induced by applying external field, i.e., temperature, electric or magnetic field.[124] For example, electrohydrodynamic instabilities utilize electric fields to overcome the stabilizing forces of surface tension and thereby form surface topography (e.g., pillars) out of molten polymer films or planar liquids with an air gap (or the other polymer film) sandwiched between two rigid electrodes (Figure 6c-f).[131-137] In general, patterns formed by instabilities are difficult to control precisely over large areas and usually result in features with characteristic length scales that lack long range order.

Light-induced chemical transformation can also create stress that results in surface topography. For example, films containing azobenzene moieties undergo a cistrans transition in response to light and generate surface topography when exposed to patterned light by employing surface-plasmon field (Figure 7).[138] It could be argued that this approach is a shape transformation rather than shape programming since the topography forms during light irradiation, but we include it since the topography is 'dormant' until stimulated by light, the response is 'programmed' within the composition of the molecules, and topography forms in the material without human (mechanical) intervention. The mechanism for this response will be discussed in more detail in section 2.3. Moreover, the surface topography can be triggered by light-induced Marangoni effect (i.e., mass transfer through the interface due to surface energy gradients). For example, the surface energy of polystyrene increases due to dehydrogenation under patterned UV irradiation so that the polymer in liquid state flows from unexposed area to exposed area to form surface feature.[139]

\section{Figure 7}


Formation of surface topographies on planar substrates can be also triggered by the shape memory effect.[32,140,141] Shape memory polymers, i.e., materials that can be programmed into a temporary shape that recover to a permanent shape upon heating, will be discussed in detail later in this review. As shown in Figure 8, surface topography can form in these structures by releasing the local stress formed by indenting or embossing, or by releasing a uniform stress generated by pre-stretching the film.[142] For example, grating patterns can be flattened into a stable temporary, flat substrate. The surface topography recovers by heating the samples above the glass transition temperature $\left(\mathrm{T}_{\mathrm{g}}\right)$ of the polymer (Figure 9).[140] Light diffraction due to the grating pattern reappears, as evident from the apparent color change of the surface. Moreover, the surface topography recovered from a shape memory polymer can form a multi-use dry adhesive to a glass substrate that is strong and reversible.[29]

Shape memory materials are also applied widely for forming 3D structures in a responsive fashion, which will be elaborated in more detail in the section 2.4.

\section{Figure 8}

\section{Figure 9}

\subsection{Bending (Strategy 3)}

This section focuses on bending as a mechanism to form out-of-plane 3D structures. Expansion (e.g., swelling, thermal expansion and pneumatics) and contraction (e.g., deswelling, thermal shrinkage, and deflation) generate usually stresses necessary to convert 2D polymer sheets into 3D shapes by bending.

Polymer gels (or polymer networks) are often used for bending because they can swell dramatically in the presence of 'good' solvents and contract when exposed to poor solvents while retaining their overall network structure. Polymer gels can be classified as either hydrogels or organogels. Hydrogels are hydrophilic polymeric networks that can absorb water and swell.[143,144] Hydrogels are noted for their ability to swell or deswell in response to environmental changes in aqueous environments including $\mathrm{pH}$, temperature, ionic strength, solvent type, or electrical potential.[143-150] These environmental cues can be employed as stimuli to induce shape change. 
Temperature is an appealing stimulus for altering the swelling behavior of hydrogels because it is easy to control and reverse externally. While technically all polymers undergo conformational changes in response to temperature, in some cases changes of polymer solubility in water are are very dramatic and lead to large changes in swelling. Poly(N-isopropylacrylamide) (PNIPAAm) and its derivatives are popular temperature-responsive hydrogels due to a reversible coil-to-globule transition that occurs upon exceeding the lower critical solution temperature (LCST $\approx 32^{\circ} \mathrm{C}$ ).[143,144,151-154] Other hydrogels also exhibit LCST.[155,156], for example, poly(N-vinylcaprolactam) or poly(N-vinylpyrrolidone).

Hydrogels often contain charged (i.e., strong polyelectrolytes) or chargeable (i.e., weak polyelectrolytes) groups. The presence of charges causes gels to swell in water. The concentration of chargeable groups in weak polyelectrolytes depends on the nature of the polymer (i.e., polycation vs. polyanion), $\mathrm{pH}$, and ionic strength of the solution. Changing the $\mathrm{pH}$ of the solution (for weak polyelectrolytes) and/or ionic strength (for all polyelectrolytes) alters the swelling behavior of the gel and are therefore useful stimuli for gel shape change.[148,157,158]

The ability to control the degree of swelling or de-swelling in hydrogels using external stimuli offers opportunities to program shape change. Isotropic swelling or deswelling results in uniform changes in volume; i.e., each dimension of the gel shrinks or expands proportionally. To induce out of plane motion, the generated stress must be asymmetric, which can be induced by employing a number of approaches.

One approach to achieve asymmetry may be realized by laminating bimorph structures with different responses to the same stimuli (i.e., temperature, solvent, ionic strength) or by patterning stimuli-responsive hydrogels.[23,154,159-162] The mismatch in mechanical response of the two layers in the bilayer governs the folding behavior in response to an external stimulus. A theoretical analysis pertaining to the bending behavior of bilayered laminates offers useful insight into folding, which is induced by mismatch in stress (or strain) between the two layers. The bending curvature of bilayered systems offers a measure of the effect of stress (or strain).

The general theory of bilayer bending is derived from the model of a bi-metallic strips proposed originally by Timoshenko in 1925.[163] A classic example of a bilayer 
structure is a thermal bimorph, featuring two layers of materials with different thermal expansion coefficients. The bilayer curls in response to heat since one layer expands more than the other. This concept may also be employed in polymeric systems; a laminate structure composed of a layer of hydrophobic polymer (i.e., polycaprolactone) and a layer of thermo-responsive hydrogel (e.g., PNIPAAm) can bend to generate a 3D structure by tuning the solution temperature (Figure 10a).[160] Similarly, a closed micro-cage made of an SU8 epoxy (high thermal expansion coefficient) laminated with diamond-like carbon (DLC) layer (low thermal expansion coefficient) can open upon heating.[164] In addition, the curvature of bilayer structures can be controlled by employing patterned polymers with various Young's moduli on the active layer which is stimuli responsive. (Figure 10b). [165] Humidity can also trigger the bending of bilayer structures. For example, a bilayer laminate comprising cross-linked poly(acrylic acid) and a layer of polymer that absorbs water from humid air (e.g., poly(allylamine hydrochloride)) will bend in response to humidity.[166-168] Hydrogel bilayers with a copolymerized layer of N-isopropylacrylamide (NIPAm) and acrylic acid (AAc) or polyhydroxyl ethyl methacrylate (HEMA) show asymmetric swelling and trigger 3D structures in solutions with different $\mathrm{pH}$ and ionic strengths.[23]

\section{Figure 10}

Another approach to bending creates out-of-plane motion by generating crosslink patterns in a hydrogel.[169] The process utilizes "halftone" photolithography of photocrosslinkable PNIPAAm copolymers containing pendent benzophenone units for crosslinking to induce the crosslink patterns. The crosslinked regions of the gel swell less than the rest of the gel, which generates the stress necessary for out of plane deformation with nearly constant Gaussian curvature (Figure 10c).[170] Various 3D shapes form by bending if the stress distribution on the film can be controlled. [171-175] For example, hydrogels can form complex 3D helical structures using sheets with alternating stripes of different chemical composition and thus different swelling response (Figure 10d).[176] In addition, chemical oscillations of ruthenium ions between reduced and oxidized states within gels can cause cyclic swelling.[177] 
Materials containing gradients of fillers or crosslinks through the depth of the sheet also bend. The asymmetry of these embedded active materials results in out-ofplane motion in response to a uniform stimulus (Figure 11).[178-183] For example, rolling of a photo-crosslinkable copolymer based on PNIPAAm can be triggered thermally in aqueous medium by patterning both high and low swelling regions using UV light (Figure 3b).[170,179]

\section{Figure 11}

Electric fields represent another attractive stimulus that can moderate swelling of polymeric gels. Electric fields can disrupt the distribution of ions in gels and therefore change the local osmotic pressure. Significant effort in this field has been achieved during the past few decades following the pioneering work by Tanaka and colleagues. $[92,184]$. For example, electrical potential can drive cations from the electrolyte (e.g., sodium dodecylbenzenesulfonate, $\mathrm{Na}^{+} \mathrm{DBS}^{-}$) into a polymer and cause asymmetrical swelling. [185,186] More recently 'ionoprinting' was introduced to introduce local folding and global bending of flat hydrogel sheets. Ionoprinting uses metal electrodes under anodic conditions to inject ions into a polyelectrolyte hydrogel (e.g., sodium polyacrylate). $[147,187,188]$ Divalent metal cations $\left(\right.$ e.g., $\left.\mathrm{Cu}^{2+}\right)$ bind within the anionic network to form crosslinks that generate sufficient mechanical stress to create a hinging response in air (Figure 12a). Whereas actuation of most gels relies on swelling/deswelling, which is a slow process, ionoprinting results in rapid actuation (a few seconds) without the need for submersion in electrolyte. In addition, the ionoprinted lines are stiffer than the rest of the gel. These stiff lines can generate an anisotropic response to de-swelling of the gel in ethanol (i.e., the water diffuses out of the gel), as shown in Figure 12b.

\section{Figure 12}

Organogels, i.e., crosslinked polymer networks that swell in the presence of organic solvents, can also be utilized for shape programming. [189-191] For example, many elastomers such as those based on poly(dimethylsiloxane) (PDMS) [192] swell to different extents based on the solubility of solvents in the networks. 
The major appeal of swelling/de-swelling for controlling the shape of a polymer sheet is its simplicity and ability to operate in wet environments. Furthermore, many hydrogels are biocompatible because they are largely composed of water. Swelling/deswelling, however, suffers from least two notable drawbacks: 1) it requires solvent media, and 2) it is generally slow due to the reliance on diffusion of solvent into the polymer (although approaches like ionoprinting can operate in air). Here, we limit the discussion of gels because there is a rich literature describing strategies (temperature, solvent, electrical potential, $\mathrm{pH}$, etc.) for shape programmable gels; the examples given here are just illustrative and not comprehensive.[12,143,144,146,152,153,193-196]

In addition to swelling, pneumatics can also induce out of plane motion from a $2 \mathrm{D}$ substrate via the volumetric expansion and contraction achieved by applying pressurized gas inside a cavity (e.g., a balloon) made of elastomeric materials such as PDMS and Ecoflex (a commercial elastomer) to be utilized as grippers (Figure 13).[24,197-200] To realize bending, asymmetrical inflation has to be achieved using material and design strategies. A downside of this method is the inconvenience of tethering of the inlets/outlets for the gas, although it is possible to induce chemical reactions to rapidly create gas in situ.[201]

\section{Figure 13}

Liquid crystal elastomers (LCEs) are popular shape programmable polymers. Whereas there are few strategies for creating shape reversible SMPs, LCEs can actuate reversibly, which is a salient feature. LCEs are hybrid materials, which combine oriented liquid crystals and polymeric elastomers. Usually, chemical synthesis couples the liquid crystal units with polymer chains to form the LCE networks. Polymer chains in the network experience anisotropic conformation due to the crystalline phase of liquid crystals, while the polymer chains return to their coil conformation upon heating. Therefore, the shape change in LCEs can be triggered by a temperature jump (Figure 14a).[202-210] LCEs incorporating photoresponsive functional groups constitute another large group of light-induced shape programmable materials (Figure 14b).[202-208,211] Many excellent reviews and books have summarized the development in this field.[204,212-217] 


\section{Figure 14}

Light can also induce shape changes to polymers by incorporating photosensitive groups, such as such as azobenzene. Photoresponsive SMPs (or so-called light-activated SMPs) involve materials with photosensitive functional groups or fillers in the polymer networks, such as photoisomerizable molecules, i.e., azobenzenes, triphenylmethane leuco derivatives, and photoreactive molecules (Figure 15a-c).[218-225] Triggered by appropriate UV wavelengths, the photoinduced effects on the molecular level (e.g., photoisomerization, ionic dissociation, or photodimerization) lead to macroscopic volume changes (shrinking or swelling) of polymers. For example, the cis-trans isomerization reactions of azobenzene generate reversible conformation changes at the molecular level in response to specific wavelengths and, in turn, induce shape change macroscopically. Azobenzene molecules may be introduced into liquid crystal elastomers [205,206,226228] or photosensitive polymer films.[5,138,229,230] Figure 15d demonstrates bending of the polymer sheet with azobenzene molecules in response to light polarized at different angles.

\section{Figure 15}

It is also possible to use electric fields to actuate elastomers and dielectric polymers by a number of mechanisms including the Maxwell stress. These topics have been reviewed elsewhere [231-236]. Likewise, piezoelectrics can convert voltage signals into displacement, but involve generally ceramic materials (with the noted exception of poly(vinylidene fluoride), PVDF [237-243]) (Figure 16). We thus do not review them in detail here but mention them for thoroughness.

\section{Figure 16}

The examples we have provided within Strategy 3 rely primarily on bulk changes in volume to induce bending. However, it is possible to localize those changes to just the surface. Changes in surface topography can be induced by employing polymer brushes

that behave similarly to gels by responding to external stimuli, such as, $\mathrm{pH}$, temperature, salt concentration, or type of solvent; those structures have been reviewed 
before.[153,245,246] The conformational change of brushes due to an external trigger can be employed in controlling surface wettability,[247,248] or adhesion properties.[249,250] The changes in surface topography due to brush expansion or contraction are relatively small compared to the other techniques discussed here and we therefore limit our discussion of this topic.

\subsection{Folding (Strategy 4)}

While there is some phenomenological overlap with the examples of bending in Strategy 3, Strategy 4 is distinguished by its focus on folding as defined in Figure 2.

Folding occurs commonly in nature (e.g., certain sensitive plants close their leaves in response to gentle touch; folding and unfolding of leaves and wings) and in the ancient art of paper folding.[251-253] Here, we discuss folding of polymeric materials using external stimuli in a hands-free manner; these approaches are often called 'selffolding'. It is a deterministic self-assembly approach that converts a $2 \mathrm{D}$ template with pre-defined hinges into a 3D shape in response to an external stimulus, as shown in Figure 17.[57] Hinges are regions on the substrate that get activated (i.e., fold) in response to an external stimulus.[57] for the need for reconfigurable devices, actuators, and sensors motivates research on folding utilizing different driving forces and a variety of active (i.e., stimuli responsive) materials.[4,14,20,57,175,186,252,254-256] While strategies can originate from or be inspired by biological systems, the approach discussed here will not include cases of responsive biomolecules or living organisms, although they can be applied for folding processes as well.[257-264]

\section{Figure 17}

Folding can be achieved by at least three means: 1) defining locally responsive hinges fabricated using materials with a different composition from the rest of the sheet; 2) combining, laminating, and patterning non-responsive sheets with responsive sheets; 3) modifying physically an otherwise homogeneous sheet (e.g., shape memory polymers) in local regions to define hinges that fold upon exposure to the external stimuli; 4) stimuli can be applied to only the hinge region of a sheet or composite (e.g., Joule heating, focused laser).[20,254,265,266] The following paragraphs describe these different means. 
One approach to fold 2D substrates is to define hinges that differ in chemical composition from the rest of the sheet. These hinged regions may be composed of a variety of materials that actuate in response to an external stimulus. For example, polyimide shrinks at high temperatures $\left(\right.$ e.g., $\left.>200^{\circ} \mathrm{C}[165,166]\right)$ due to out-gassing of strongly-bound solvents (Figure 18a). Likewise, pre-strained polymer films shrink upon heating and can be utilized as local hinges different from the bulk materials to induce folding (Figure 18b).[269] Stimuli-responsive polymers patterned as hinges can also control folding and unfolding of non-responsive laminates (Figure 18c).[38] For instance, a polymer (e.g., poly(caprolactone) [270]) or molten metal (e.g., solder $[36,271])$ can be patterned as a hinge and cause folding of polymer sheets when heated due to surface tension. Some gels swell in response to selected solvents and may therefore be used as hinges as well. For example, hydrophilic hinges based on polyurethane (PU)/2-hydroxyethyl methacrylate (HEMA) swell significantly in acetic acid for folding planar sheets of PDMS into of 3D structures.[175]

\section{Figure 18}

Another approach employed to fold planar sheets applies multilayer laminates comprised of responsive films combined with non-responsive, rigid films that locally limit deformation. Figure 19a shows a schematic of rigid plates held together by a shrink film which can actuate in response to an external stimulus. The folding angle can be controlled by the gap distance, thickness and shrinkage (or swelling) of the active sheet.[2,272-277] One implementation of this strategy consists of sandwiching a temperature responsive hydrogel (e.g., PNIPAAm) sandwiched between two glassy polymer layers. Patterned openings in the top glassy layer allow the gel to swell only locally and therefore create a hinging response, which enables micro-scale origami including the creation of the classic origami crane (Figure 19b). A similar strategy sandwiches a pre-strained thermoplastic between two layers of structural panels. When placed in an oven, the thermoplastic shrinks only in the gap between the panels (Figure 19c). Folding occurs due to asymmetric openings in the panels. Another example is bonding the elastomeric polymers with a layer of magnetic material and fold can be 
induced in response to external magnetic fields. [279] This approach requires multiple (yet simple) fabrication steps and results in folds that are very reproducible.

\section{Figure 19}

A third approach to fold planar sheets utilizes physical pre-programming of chemically homogeneous substrates. For example, thermally-responsive SMPs can be locally pre-programmed to a temporary shape and return back to a permanent shape at $\mathrm{T}>\mathrm{T}_{\text {trans }}$ to achieve shape changing from $2 \mathrm{D}$ to $3 \mathrm{D}$. The heat may be delivered by using either uniform or local stimuli, including focused light, Joule heating, or thermal radiation. [280,254,281-286] An illustrative example is shown in Figure 20.

\section{Figure 20}

In general, shape memory materials have been used extensively for 3D shape programming. These structures demonstrate the so-called shape memory effect in response to various external stimuli. The shape memory effect describes a phenomenon wherein a material can return to its original shape from a temporary shape, defined by deforming the material and fixing it in a metastable state.[287] The temporary shape does not have to be flat, although it can be, as shown in Figure 20. Although the final shape could be either a bend or a fold, we discuss it within Strategy 4 because it provides a popular approach for folding.

Swedish physicist Arne Olander discovered the shape-memory effect in the early 1930s in gold-cadmium (Au-Cd) alloys, which can be plastically deformed upon cooling and can return to the original shape by heating.[288] Shape memory materials include not only metal alloys but also other materials such as ceramics, liquid crystalline elastomers, polymers, and gels.[202,203,289-292] Shape memory alloys (SMA) and shape memory polymers (SMPs) are two of the most popular shape memory materials, which will only be briefly introduced here since they have been reviewed thoroughly in the literature.[287-289,293-299]

Although SMAs are not necessarily polymeric, they may be combined strategically with polymer sheets to program shape changes. The most common SMA is nickel-titanium alloy (Nitinol) [288,289,280,300] Those metal alloys demonstrate the 
shape-memory effect due to the thermally-driven reversible phase transition from a symmetrical austenitic phase at high temperatures to an asymmetrical martensitic phase.[287,289,280] SMAs can be patterned as thin films to deflect substrates into 3D structures,[301-305] or as actuating hinges that induce the folding of 2D planes when heated (Figure 21).[20,254]

\section{Figure 21}

SMPs were first developed commercially in 1980s and received much attention due to their light weight, flexibility, high transformation strain, and low actuation forces compared to similar properties observed in metal alloys.[280] SMPs possess a great potential in a variety of applications such as automatic switches or sensors, intelligent packaging and tissue engineering, and have been reviewed thoroughly.[281,282,289,294296,298,306-315] Both the molecular architecture of polymers and the "programming process" govern the shape memory behavior of SMPs. A typical programming process uses a thermo-mechanical cycle (Figure 22a) that starts with the polymer in the permanent shape, deforms the polymer to a temporary shape by applying an external

force over the thermal transition temperature $\left(\mathrm{T}_{\text {trans }}\right)$ (e.g., $\mathrm{T}_{\mathrm{g}}$ or melting temperature, $\mathrm{T}_{\mathrm{m}}$ ), and cools the polymer to preserve that temporary structure. Upon heating above $\mathrm{T}_{\text {trans, }}$, the polymer recovers to the permanent shape (i.e., the recovered shape) because the polymer chains relax back to the entropically favorable state. The shape memory effect is commonly characterized by a cyclic thermo-mechanical strain-temperature-stress diagram (Figure 22b). [316] The strain recovery rate, which describes how much the polymer memorizes the permanent shape, and the strain fixity rate, which shows how well the polymer can be fixed at the temporary shape, quantifies the shape memory performance.[287] Most SMPs have one temporary shape. Several researchers have developed clever ways to introduce more than one temporary shape into a SMP.[317321]

\section{Figure 22}

As shown in Figure 23, the ability for polymer to "remember" its permanent shape relies on cross-links in the form of either covalent bonds (i.e., chemical cross- 
linking) or strong intermolecular interactions (e.g., chain entanglement or crystalline domains). So-called "switching segments" fix the temporary shape of the polymer network and prevent the flow of polymer chains below the transition temperature. Although Figure 23 summarizes switching approaches, the most common switching segments are "frozen" polymer chains at $\mathrm{T}<\mathrm{T}_{\mathrm{g}}$ for amorphous polymers or polymers in crystalline domains at $\mathrm{T}<\mathrm{T}_{\mathrm{m}}$ for semi-crystalline polymers. [280,287,309,310]

Some macroscopically-homogeneous planar materials adopt 3D shapes under uniform stimuli due to the gradients of crosslink densities that form across the sheet in response to a uniform stimulus (e.g., light, heat, etc.) (Figure 24).

\section{Figure 23}

\section{Figure 24}

In addition, stimuli can be applied locally to the hinge region, by, for example, Joule heating, [20,254,322] focused laser light, [265,266] or pneumatics. [323]

Recently, our group reported on a simple approach to achieve folding using homogeneous 2D pre-strained polymer sheets with inkjet-printed hinges on a planar surface.[324] Pre-strained polymer sheets are a type of shape memory polymer that shrinks in-plane if heated uniformly. Black toner patterned on the surface provides localized absorption of light, which heats the underlying polymer to temperatures above the $\mathrm{T}_{\mathrm{g}}$ to induce the local shrinkage of the polymer so that the planar sheet folds into a $3 \mathrm{D}$ shape. Various 3D structures have been demonstrated using this approach from simple folding to complex structures (Figure 25) and a simple geometric model predicts its folding angle based on strain relaxation.[325] It is also possible to induce the folding by irradiating the samples with light patterned in the shape of a hinge.[266]

\section{Figure 25}

\subsection{Discussion for out-of-plane shape programming (Strategies 3 and 4)}

The approaches described in Strategies 3 and 4 often present trade-offs. For example, patterned hinges frequently require multiple fabrication steps but can result in a range of complex 3D structures (Figures 18 \& 21). In contrast, bilayer laminates are simple, but deform into a limited set of geometries and only produce sharp folds when combined 
with patterned, rigid sheets (Figure 19). SMPs require pre-programming and are usually actuated by heating (Figure 20). Hydrogels are biocompatible but their use is usually limited to liquid environments and materials that are often very soft. Thermal actuation is one of the most popular means to induce folding or bending due to its simplicity and the availability of thermal triggers (i.e., light, resistive heating and thermal radiation), but the high temperatures required often limit the applicability of such structures. More generally, selecting materials for shape programming often presents a trade-off between elastic strain and modulus. Figure 26 summarizes the mechanical characteristics of a wide range of existing materials applied for reconfigurable and morphing structures.[326-328] The red dashed curve in the upper right corner of Figure 26 depicts the trade-off between strain and stiffness for those structures. Materials that can be deformed significantly (i.e., large strain) tend to have a lower modulus, which limits their utility. Polymers included in the diagram in Figure 26 are no exception; elastomers or gels possess a low modulus and can be extended to large strains. For many applications, it is desirable to have large deformations and large moduli to store mechanical energy. Development of materials that meet these criteria represents a great research challenge as well as opportunity.

\section{Figure 26}

\section{Table 1}

Table I summarizes representative stimuli for folding and bending of polymeric materials typical materials, length scales, and reversibility. [4,57,288,255] Among all parameters listed in Table I, reversibility is one of top considerations for realizing practical applications of out-of-plane actuation. Hydrogels, electroactive polymers, and LCEs have exhibited various degrees of reversibility. Swelling/de-swelling of gels is a reversible process but it takes place typically only in liquid environments, diffusion of liquid in and out of the gel limits the rate of actuation, and gels are typically soft and brittle. The actuation of photoresponsive shape memory polymers and liquid crystal elastomers with photosensitive groups is reversible by switching the exposure wavelengths (usually in the UV range). Bilayers with differential thermal expansion 
bend reversibly over small displacements. In contrast, the folding of most SMPs is usually irreversible (i.e., the so-called one-way shape memory effect) due to the strain relaxation that occurs. Likewise, actuation of pre-strained polymers is typically irreversible because the first actuation relaxes (often completely) the stored strain. Several recent reports discuss polymers with two-way shape memory effects.[310,329338] The term 'two-way' implies that the polymers can change shape reversibly multiple times simply by changing the stimulus. The two-way shape memory effect has been explored in semicrystalline polymers. [310,329,330,332,336,337,339-345] In general, these systems shrink due to chain relaxation at elevated temperature, but revert to a different shape due to stresses generated by the reformation of crystals at lower temperatures.

Response time for folding is an important parameter not listed in Table I. Swelling/de-swelling in solvents is usually slow due to inherently slow diffusion process which takes minutes to hours. Chemical changes induced by light cause folding relatively slow (few minutes). Pneumatic actuation occurs typically within seconds or less and can be done reversibly. Actuation in magnetic field is also relatively fast (seconds), and can be done reversibly. Thermal actuation (including light irradiation for heating) can also be fast (a few seconds).

Another challenge facing the field of out-of-plane actuation is the relatively simple 3D structures that have been demonstrated to date, such as single folds and cubes. There are some more complex structures beginning to appear in the literature. [277,279] The ability to provide sequential folding of hinges (rather than all hinges folding at once) may help increase the level of complexity.

Although most current research on converting 2D planar sheets to 3D out-ofplane structures by folding does not use paper, it is often called 'origami engineering' which covers a wide range of topics including development of responsive materials, the study of algorithms and mechanics for designing folded structures, [346-353] the establishment of physical models (e.g., to predict and understand compliant mechanisms and its link to origami folding[354-358]), the development of new design tools for fabrication, [359] and the implementation of novel concepts for structure or topography optimization (e.g., hinge design and layout, folding sequence, reconfiguration).[360-362] 
In summary, currently there is no universal, ideal approach that provides reversibility, fast response, large forces or torques, geometric and sequential control, and ease of fabrication. Realizing systems that have most or all of these properties is a primary goal of materials researchers working on shape programming.

\section{6}

\subsection{Applications for out-of-plane shape programming (Strategies 3 and 4)}

Out-of-plane shape transformation from $2 \mathrm{D}$ to $3 \mathrm{D}$ is an appealing strategy to generate $3 \mathrm{D}$ structures from 2D patterns for many applications spanning microscale to macroscale. Examples include containers for drug delivery and biomedical devices,[25,38,255,281,381-385]; actuators, grippers and robotics (Figure 27a); $[24,164,185,186,363,364,386]$ robotic microhand or minimally invasive surgery; [26,257,281,387-390] optical sensors and devices; [22,32,265,391] 3D microfluidic devices (Figure 27b); [178,392,393] reconfigurable devices or robots; [20,33,68,254,322,394-396] adhesives and interlocks [29,397] nanoinjector; [398] programmable lithography for nanostructures [399] smart packaging; deployable structures (Figure 27c); [251,400-404] and shape-shifting mobile devices.[28]

\section{Figure 27}

\section{Conclusion, opportunities, and challenges for shape programming}

Shape-programming of materials from 2D sheets to 3D shapes is appealing in many applications including reconfigurable devices, responsive actuators, and assembly processes. This review motivates the advantages of creating $3 \mathrm{D}$ shapes from $2 \mathrm{D}$ sheets and introduces several representative strategies and mechanisms for shape programming polymeric materials involving out-of-plane deformation, i.e., folding, bending, rolling, contraction, expansion, induced surface topography, and conventional lithographic processes. This review focuses primarily on strategies for out-of-plane actuation, of polymeric materials from $2 \mathrm{D}$ sheets to $3 \mathrm{D}$ shapes, as well as relevant programmable materials within the context of folding.

Although great progress has been made toward shape programmable materials and relevant methods from $2 \mathrm{D}$ to $3 \mathrm{D}$, there many opportunities still exist for new shape 
programming approaches, especially folding/bending, to evolve regarding design optimization and materials development.

In this context, novel strategies need to be developed that lower the complexity of fabrication of folding substrates, without the loss of high fidelity (i.e., with few defects such as over-folding or under-folding). Many current strategies rely on multi-step microfabrication processes. Second, the most popular stimulus is thermal actuation due to its ease of implementation. However, other stimuli such as chemical and mechanical responses are also desired. Third, although efforts have been made to control and program the folding pathways, [20,254,265,405-407] there more opportunities exist to better control the folding/unfolding pathways that may lead to sequential or programmed folding to create more complex geometries and more sophisticated applications, which is interesting for "4D assembly" (i.e., 3D structures that change shape with time) or printing where the motion or shape is highly correlated with time as well $[80,408,409]$. Fourth, the rate of folding could be improved along with precise control over folding dynamics. Employing strategies such as snap-buckling instabilities (e.g., those employed by the Venus fly trap $[161,410,411]$ ) may allow for more rapid folding relative to mechanisms that rely on polymer shrinkage or gel swelling, which are generally slow. In addition, most folding occurs slowly and often requires large inputs of energy, which represents new opportunities for optimization and improvement. Fifth, the actuation associated with many folding strategies does not generate significant force (or torque), which limits the utility. Lastly, effort in modeling and folding algorithms is needed to guide the optimal design of folding/bending processes.

Current materials and processes often do not meet the needs of applications. For example, shape reversible materials are desired for practical applications that call for reconfigurability. Many current polymers undergo irreversible shape change in response to a stimulus (e.g., shape change usually represents a minimization of energy), while the approaches and materials that are reversible are limited to a narrow range of external stimuli that are often inconvenient such as large changes in temperature or the need to operate in a liquid environment (for controlling $\mathrm{pH}$, ionic concentration). Thus, there are opportunities to develop new polymers or mechanisms for reversible shape change. 
There are also opportunities for modelers and theoreticians to provide guidance for optimized design. Most applications are case-dependent regarding materials selection and stimuli utilization. The performance metrics (e.g., energy efficiency, performance versus fabrication complexity and economic costs, pathway, accuracy, fidelity, durability, packing ratio) should guide the design strategy and materials selection.

\section{Acknowledgements}

We thank the National Science Foundation for supporting this work under the grant No. 1240438. We also thank our collaborators in the NSF EFRI program and beyond for many fruitful interactions during the past few years. 


\section{References}

[1] Lauff C, Simpson TW, Frecker M, Ounaies Z, Ahmed S, von Lockette P, Strzelec R, Sheridan R, Lien JM. Differentiating Bending From Folding in Origami Engineering Using Active Materials. ASME Proc. 2014. p. V05BT08A040.

[2] Peraza-Hernandez EA, Hartl DJ, Malak Jr RJ, Lagoudas DC. Origami-inspired active structures: a synthesis and review. Smart Mater Struct 2014;23:094001/128.

[3] Abbott AC, Buskohl PR, Joo JJ, Reich GW, Vaia RA. Characterization of Creases in Polymers for Adaptive Origami Structures. ASME Proc. 2014. p. V001T01A009.

[4] Ionov L. Soft microorigami: self-folding polymer films. Soft Matter 2011;7:678691.

[5] Ryu J, D'Amato M, Cui X, Long KN, Qi HJ, Dunn ML. Photo-origami-Bending and folding polymers with light. Appl Phys Lett 2012;100:161908/1-5.

[6] Chen D, Yoon J, Chandra D, Crosby AJ, Hayward RC. Stimuli-responsive buckling mechanics of polymer films. J Polym Sci Part B Polym Phys 2014;52:1441-61.

[7] Kempaiah R, Nie Z. From nature to synthetic systems: shape transformation in soft materials. J Mater Chem B 2014;2:2357-68.

[8] Gracias DH. Stimuli responsive self-folding using thin polymer films. Curr Opin Chem Eng 2013;2:112-9.

[9] Vaia R, Baur J. Materials Science: Adaptive Composites. Science 2008;319:4201.

[10] Geryak R, Tsukruk VV. Reconfigurable and actuating structures from soft materials. Soft Matter 2014;10:1246-63.

[11] Ionov L. Biomimetic Hydrogel-Based Actuating Systems. Adv Funct Mater 2013;23:4555-70.

[12] Ionov L. Polymer origami: programming the folding with shape. E-Polym 2014;14:109-14.

[13] Ionov L. Polymeric Actuators. Langmuir 2015;31:5015-24. 
[14] Ionov L. Bioinspired Microorigami by Self-Folding Polymer Films. Macromol Chem Phys 2013;214:1178-83.

[15] Ionov L. 3D Microfabrication using Stimuli-Responsive Self-Folding Polymer Films. Polym Rev 2013;53:92-107.

[16] Ionov L. Hydrogel-based actuators: possibilities and limitations. Mater Today 2014;17:494-503.

[17] Dealy JM, Wissbrun KF. Melt rheology and its role in plastics processing: theory and applications. Dordrecht: Springer Netherland, 1990. 665 pp.

[18] Rosato DV. Plastic product material and process selection handbook. New York, USA: Elsevier 2004. 618 pp.

[19] Madou MJ. Fundamentals of microfabrication: the science of miniaturization. 2nd ed. Boca Raton FL: CRC Press, 2002. 723 pp.

[20] Hawkes E, An B, Benbernou NM, Tanaka H, Kim S, Demaine ED, Rus D, Wood RJ. Programmable matter by folding. Proc Natl Acad Sci 2010;107:12441-5.

[21] Khan MR, Hayes GJ, So JH, Lazzi G, Dickey MD. A frequency shifting liquid metal antenna with pressure responsiveness. Appl Phys Lett 2011;99:013501/1-3.

[22] Cho JH, Keung MD, Verellen N, Lagae L, Moshchalkov VV, Van Dorpe P, Gracias DH. Nanoscale Origami for 3D Optics. Small 2011;7:1943-8.

[23] Bassik N, Abebe BT, Laflin KE, Gracias DH. Photolithographically patterned smart hydrogel based bilayer actuators. Polymer 2010;51:6093-8.

[24] Ilievski F, Mazzeo AD, Shepherd RF, Chen X, Whitesides GM. Soft Robotics for Chemists. Angew Chem Int Ed 2011;50:1890-5.

[25] Small W, Wilson TS, Benett WJ, Loge JM, Maitland DJ. Laser-activated shape memory polymer intravascular thrombectomy device. Opt Express 2005;13:820413.

[26] Small, IV W, Singhal P, Wilson TS, Maitland DJ. Biomedical applications of thermally activated shape memory polymers. J Mater Chem 2010;20:3356-66.

[27] Kuribayashi K, Tsuchiya K, You Z, Tomus D, Umemoto M, Ito T, Sasaki M. Self-deployable origami stent grafts as a biomedical application of Ni-rich TiNi shape memory alloy foil. Mater Sci Eng A Struct Mater 2006;419:131-7. 
[28] Roudaut A, Karnik A, Löchtefeld M, Subramanian S. Morphees: toward high "shape resolution" in self-actuated flexible mobile devices. In: Bødker S, Brewster S, editors. Proc SIGCHI Conf Hum Factors Comput. Syst. Paris, France: ACM Press, 2013. p. 593-602.

[29] Eisenhaure JD, Xie T, Varghese S, Kim S. Microstructured Shape Memory Polymer Surfaces with Reversible Dry Adhesion. ACS Appl Mater Interfaces 2013;5:7714-7.

[30] Blewitt MJ, Willits RK. The Effect of Soluble Peptide Sequences on Neurite Extension on 2D Collagen Substrates and Within 3D Collagen Gels. Ann Biomed Eng 2007;35:2159-67.

[31] Efimenko K, Finlay J, Callow ME, Callow JA, Genzer J. Development and Testing of Hierarchically Wrinkled Coatings for Marine Antifouling. ACS Appl Mater Interfaces 2009;1:1031-40.

[32] Xu H, Yu C, Wang S, Malyarchuk V, Xie T, Rogers JA. Deformable, Programmable, and Shape-Memorizing Micro-Optics. Adv Funct Mater 2013;23:3299-306.

[33] Hayes GJ, Liu Y, Genzer J, Lazzi G, Dickey MD. Self-Folding Origami Microstrip Antennas. IEEE Trans Antennas Propag 2014;62:5416-9.

[34] Xia Y, Rogers JA, Paul KE, Whitesides GM. Unconventional Methods for Fabricating and Patterning Nanostructures. Chem Rev 1999;99:1823-48.

[35] Reichmanis E, Houlihan FM, Nalamasu O, Neenan TX. Chemically amplified resists: Chemistry and processes. Adv Mater Opt Electron 1994;4:83-93.

[36] Leong TG, Lester PA, Koh TL, Call EK, Gracias DH. Surface Tension-Driven Self-Folding Polyhedra. Langmuir 2007;23:8747-51.

[37] Cho JH, Gracias DH. Self-Assembly of Lithographically Patterned Nanoparticles. Nano Lett 2009;9:4049-52.

[38] Leong TG, Randall CL, Benson BR, Bassik N, Stern GM, Gracias DH. Tetherless thermobiochemically actuated microgrippers. Proc Natl Acad Sci 2009;106:7038.

[39] Kern W. Thin film processes II. Boston: Academic Press 1991. 866 pp.

[40] Thornton JA. High Rate Thick Film Growth. Annu Rev Mater Sci 1977;7:239-60. 
[41] Kovacs GTA, Maluf NI, Petersen KE. Bulk micromachining of silicon. Proc IEEE 1998;86:1536-51.

[42] Bustillo JM, Howe RT, Muller RS. Surface micromachining for microelectromechanical systems. Proc IEEE 1998;86:1552-74.

[43] Gates BD, Xu Q, Love JC, Wolfe DB, Whitesides GM. Unconventional nanofabrication. Annu Rev Mater Res 2004;34:339-72.

[44] Rogers JA, Lee HH, editors. Unconventional nanopatterning techniques and applications. Hoboken NJ: John Wiley \& Sons Inc, 2009. 617 pp.

[45] Guo LJ. Recent progress in nanoimprint technology and its applications. J Phys Appl Phys 2004;37:R123-41.

[46] Guo LJ. Nanoimprint Lithography: Methods and Material Requirements. Adv Mater 2007;19:495-513.

[47] Costner EA, Lin MW, Jen WL, Willson CG. Nanoimprint Lithography Materials Development for Semiconductor Device Fabrication. Annu Rev Mater Res 2009;39:155-80.

[48] Chou SY. Nanoimprint lithography. J Vac Sci Technol B Microelectron Nanometer Struct 1996;14:4129-33.

[49] Schift H. Nanoimprint lithography: 2D or not 2D? A review. Appl Phys A 2015; in press DOI:10.1007/s00339-015-9106-3,

[50] Ruiz R, Kang H, Detcheverry FA, Dobisz E, Kercher DS, Albrecht TR, de Pablo JJ, Nealey PF. Density Multiplication and Improved Lithography by Directed Block Copolymer Assembly. Science 2008;321:936-9.

[51] Piner RD, Zhu J, Xu F, Hong S, Mirkin CA. “Dip-Pen” Nanolithography. Science 1999;283:661-3.

[52] Sullivan AC, Grabowski MW, McLeod RR. Three-dimensional direct-write lithography into photopolymer. Appl Opt 2007;46:295.

[53] Yang SM, Jang SG, Choi DG, Kim S, Yu HK. Nanomachining by Colloidal Lithography. Small 2006;2:458-75.

[54] Zhang G, Wang D. Colloidal Lithography-The Art of Nanochemical Patterning. Chem - Asian J 2009;4:236-45.

[55] Xia Y, Whitesides GM. Soft Lithography. Annu Rev Mater Sci 1998;28:153-84. 
[56] Zhao XM, Xia Y, Whitesides GM. Soft lithographic methods for nanofabrication. J Mater Chem 1997;7:1069-74.

[57] Leong TG, Zarafshar AM, Gracias DH. Three-Dimensional Fabrication at Small Size Scales. Small 2010;6:792-806.

[58] Boncheva M, Bruzewicz DA, Whitesides GM. Millimeter-scale self-assembly and its applications. Pure Appl Chem 2003;75:621-30.

[59] Grzybowski BA, Wilmer CE, Kim J, Browne KP, Bishop KJM. Self-assembly: from crystals to cells. Soft Matter 2009;5:1110-28.

[60] Cerrina F. Application of X-rays to nanolithography. Proc IEEE 1997;85:644-51.

[61] Maruo S, Ikuta K. Submicron stereolithography for the production of freely movable mechanisms by using single-photon polymerization. Sens Actuators Phys 2002;100:70-6.

[62] Scott TF, Kowalski BA, Sullivan AC, Bowman CN, McLeod RR. Two-Color Single-Photon Photoinitiation and Photoinhibition for Subdiffraction Photolithography. Science 2009;324:913-7.

[63] Linnenberger A, Bodine MI, Fiedler C, Roberts JJ, Skaalure SC, Quinn JP, Bryant SJ, Cole M, McLeod RR. Three dimensional live cell lithography. Opt Express 2013;21:10269-77.

[64] Deng D, Chen Y. Origami-Based Self-Folding Structure Design and Fabrication Using Projection Based Stereolithography. J Mech Des 2015;137:021701/1-12.

[65] Lewis JA, Gratson GM. Direct writing in three dimensions. Mater Today 2004;7:32-9.

[66] Ahn BY, Duoss EB, Motala MJ, Guo X, Park SI, Xiong Y, Yoon J, Nuzzo RG, Rogers JA, Lewis JA. Omnidirectional Printing of Flexible, Stretchable, and Spanning Silver Microelectrodes. Science 2009;323:1590-3.

[67] Ladd C, So JH, Muth J, Dickey MD. 3D Printing of Free Standing Liquid Metal Microstructures. Adv Mater 2013;25:5081-5.

[68] Sun K, Wei TS, Ahn BY, Seo JY, Dillon SJ, Lewis JA. 3D Printing of Interdigitated Li-Ion Microbattery Architectures. Adv Mater 2013;25:4539-43.

[69] Katz HE. Recent Advances in Semiconductor Performance and Printing Processes for Organic Transistor-Based Electronics. Chem Mater 2004;16:4748-56. 
[70] Yin Z, Huang Y, Bu N, Wang X, Xiong Y. Inkjet printing for flexible electronics: Materials, processes and equipments. Chin Sci Bull 2010;55:3383-407.

[71] de Gans BJ, Duineveld PC, Schubert US. Inkjet Printing of Polymers: State of the Art and Future Developments. Adv Mater 2004;16:203-13.

[72] Pudas M, Halonen N, Granat P, Vähäkangas J. Gravure printing of conductive particulate polymer inks on flexible substrates. Prog Org Coat 2005;54:310-6.

[73] Kay R, Desmulliez M. A review of stencil printing for microelectronic packaging. Solder Surf Mt Technol 2012;24:38-50.

[74] Chiche A, Stafford CM, Cabral JT. Complex micropatterning of periodic structures on elastomeric surfaces. Soft Matter 2008;4:2360-4.

[75] Stafford CM, Guo S, Harrison C, Chiang MYM. Combinatorial and highthroughput measurements of the modulus of thin polymer films. Rev Sci Instrum 2005;76:062207/1-5.

[76] Yang S, Khare K, Lin PC. Harnessing Surface Wrinkle Patterns in Soft Matter. Adv Funct Mater 2010;20:2550-64.

[77] Chung JY, Nolte AJ, Stafford CM. Surface Wrinkling: A Versatile Platform for Measuring Thin-Film Properties. Adv Mater 2011;23:349-68.

[78] Chen CM, Yang S. Wrinkling instabilities in polymer films and their applications. Polym Int 2012;61:1041-7.

[79] Rodríguez-Hernández J. Wrinkled interfaces: Taking advantage of surface instabilities to pattern polymer surfaces. Prog Polym Sci 2015;42:1-41.

[80] Genzer J, Groenewold J. Soft matter with hard skin: From skin wrinkles to templating and material characterization. Soft Matter 2006;2:310-23.

[81] Efimenko K, Rackaitis M, Manias E, Vaziri A, Mahadevan L, Genzer J. Nested self-similar wrinkling patterns in skins. Nat Mater 2005;4:293-7.

[82] Okayasu T, Zhang HL, Bucknall DG, Briggs GAD. Spontaneous Formation of Ordered Lateral Patterns in Polymer Thin-Film Structures. Adv Funct Mater 2004;14:1081-8.

[83] Zhang HL, Okayasu T, Bucknall DG. Large area ordered lateral patterns in confined polymer thin films. Eur Polym J 2004;40:981-6. 
[84] Chandra D, Crosby AJ. Self-Wrinkling of UV-Cured Polymer Films. Adv Mater 2011;23:3441-5.

[85] Takahashi M, Inoue M, Ihara R, Yoko T, Nemoto T, Isoda S, Malfatti L, Costacurta S, Innocenzi P. Photo-Fabrication of Titania Hybrid Films with Tunable Hierarchical Structures and Stimuli-Responsive Properties. Adv Mater 2010;22:3303-6.

[86] Kim HS, Crosby AJ. Solvent-Responsive Surface via Wrinkling Instability. Adv Mater 2011;23:4188-92.

[87] Shih TK, Ho JR, Liao HY, Chen CF, Liu CY. Fabrication of optical gratings by shrinkage of a rubber material. Thin Solid Films 2008;516:5339-43.

[88] Bowden N, Brittain S, Evans AG, Hutchinson JW, Whitesides GM. Spontaneous formation of ordered structures in thin films of metals supported on an elastomeric polymer. Nature 1998;393:146-9.

[89] Kim J, Lee HH. Wave formation by heating in thin metal film on an elastomer. J Polym Sci Part B Polym Phys 2001;39:1122-8.

[90] Cao C, Chan HF, Zang J, Leong KW, Zhao X. Harnessing Localized Ridges for High-Aspect-Ratio Hierarchical Patterns with Dynamic Tunability and Multifunctionality. Adv Mater 2014;26:1763-70.

[91] Lin S, Lee EK, Nguyen N, Khine M. Thermally-induced miniaturization for micro- and nanofabrication: progress and updates. Lab Chip 2014;14:3475-88.

[92] Tanaka T, Sun ST, Hirokawa Y, Katayama S, Kucera J, Hirose Y, Amiya T. Mechanical instability of gels at the phase transition. Nature 1987;325:796-8.

[93] Hu Z, Chen Y, Wang C, Zheng Y, Li Y. Polymer gels with engineered environmentally responsive surface patterns. Nature 1998;393:149-52.

[94] Chung JY, Nolte AJ, Stafford CM. Diffusion-Controlled, Self-Organized Growth of Symmetric Wrinkling Patterns. Adv Mater 2009;21:1358-62.

[95] Chan EP, Crosby AJ. Spontaneous formation of stable aligned wrinkling patterns. Soft Matter 2006;2:324-8.

[96] Casper MD, Gözen AÖ, Dickey MD, Genzer J, Maria JP. Surface wrinkling by chemical modification of poly(dimethylsiloxane)-based networks during sputtering. Soft Matter 2013;9:7797-803. 
[97] Allen HG. Analysis and design of structural sandwich panels. New York: Pergamon Press 1969. 283 pp.

[98] Fredrickson GH, Ajdari A, Leibler L, Carton JP. Surface modes and deformation energy of a molten polymer brush. Macromolecules 1992;25:2882-9.

[99] Yoo PJ, Suh KY. Physical self-assembly of microstructures by anisotropic buckling. Adv Mater 2002;14:1383-7.

[100] Huang R. Kinetic wrinkling of an elastic film on a viscoelastic substrate. J Mech Phys Solids 2005;53:63-89.

[101] Yoo PJ, Lee HH. Morphological Diagram for Metal/Polymer Bilayer Wrinkling: Influence of Thermomechanical Properties of Polymer Layer. Macromolecules 2005;38:2820-31.

[102] Ohzono T, Shimomura M. Geometry-Dependent Stripe Rearrangement Processes Induced by Strain on Preordered Microwrinkle Patterns. Langmuir 2005;21:72307.

[103] Genzer J, Efimenko K. Recent developments in superhydrophobic surfaces and their relevance to marine fouling: a review. Biofouling 2006;22:339-60.

[104] Yoo PJ, Park SY, Kwon SJ, Suh KY, Lee HH. Microshaping metal surfaces by wave-directed self-organization. Appl Phys Lett 2003;83:4444-46.

[105] Chan EP, Crosby AJ. Fabricating Microlens Arrays by Surface Wrinkling. Adv Mater 2006;18:3238-42.

[106] Chandra D, Yang S, Lin PC. Strain responsive concave and convex microlens arrays. Appl Phys Lett 2007;91:251912/1-3.

[107] Stafford CM, Harrison C, Beers KL, Karim A, Amis EJ, VanLandingham MR, Kim HC, Volksen W, Miller RD, Simonyi EE. A buckling-based metrology for measuring the elastic moduli of polymeric thin films. Nat Mater 2004;3:545-50.

[108] Huang J, Juszkiewicz M, de Jeu WH, Cerda E, Emrick T, Menon N, Russell TP. Capillary Wrinkling of Floating Thin Polymer Films. Science 2007;317:650-3.

[109] Kolaric B, Vandeparre H, Desprez S, Vallée RAL, Damman P. In situ tuning the optical properties of a cavity by wrinkling. Appl Phys Lett 2010;96:043119/1-3. 
[110] Koo WH, Jeong SM, Araoka F, Ishikawa K, Nishimura S, Toyooka T, Takezoe H. Light extraction from organic light-emitting diodes enhanced by spontaneously formed buckles. Nat Photonics 2010;4:222-6.

[111] Koo WH, Jeong SM, Nishimura S, Araoka F, Ishikawa K, Toyooka T, Takezoe H. Polarization Conversion in Surface-Plasmon-Coupled Emission from Organic Light-Emitting Diodes Using Spontaneously Formed Buckles. Adv Mater 2011;23:1003-7.

[112] Kim JB, Kim P, Pégard NC, Oh SJ, Kagan CR, Fleischer JW, Stone HA, Loo YL. Wrinkles and deep folds as photonic structures in photovoltaics. Nat Photonics 2012;6:327-32.

[113] Wang Q, Zhao X. Creasing-wrinkling transition in elastomer films under electric fields. Phys Rev E 2013;88:042403/1-6.

[114] Wang Q, Zhang L, Zhao X. Creasing to Cratering Instability in Polymers under Ultrahigh Electric Fields. Phys Rev Lett 2011;106:118301/1-4.

[115] Li B, Cao YP, Feng XQ, Gao H. Mechanics of morphological instabilities and surface wrinkling in soft materials: a review. Soft Matter 2012;8:5728-45.

[116] Pocivavsek L, Dellsy R, Kern A, Johnson S, Lin B, Lee KYC, Cerda E. Stress and Fold Localization in Thin Elastic Membranes. Science 2008;320:912-6.

[117] Hong W, Zhao X, Suo Z. Formation of creases on the surfaces of elastomers and gels. Appl Phys Lett 2009;95:111901/1-3.

[118] Wang Q, Zhao X. Phase Diagrams of Instabilities in Compressed Film-Substrate Systems. J Appl Mech 2013;81:051004/1-10.

[119] Zhao X, Wang Q. Harnessing large deformation and instabilities of soft dielectrics: Theory, experiment, and application. Appl Phys Rev 2014;1:021304/1-24.

[120] Velankar SS, Lai V, Vaia RA. Swelling-Induced Delamination Causes Folding of Surface-Tethered Polymer Gels. ACS Appl Mater Interfaces 2012;4:24-9.

[121] Jin L, Auguste A, Hayward RC, Suo Z. Bifurcation Diagrams for the Formation of Wrinkles or Creases in Soft Bilayers. J Appl Mech 2015;82:061008/1-11.

[122] Gentili D, Foschi G, Valle F, Cavallini M, Biscarini F. Applications of dewetting in micro and nanotechnology. Chem Soc Rev 2012;41:4430-43. 
[123] Xue L, Han Y. Pattern formation by dewetting of polymer thin film. Prog Polym Sci 2011;36:269-93.

[124] Mukherjee R, Sharma A, Steiner U. Surface Instability and Pattern Formation in thin Polymer Films. In: del Campo A, Arzt E, editors. Generating MicroNanopatterns on Polym Materials. Weinheim: Wiley-VCH Verlag GmbH \& Co. KGaA 2011. p. 217-65.

[125] Roy S, Biswas D, Salunke N, Das A, Vutukuri P, Singh R, Mukherjee R. Control of Morphology in Pattern Directed Dewetting of a Thin Polymer Bilayer. Macromolecules 2013;46:935-48.

[126] Herminghaus S. Spinodal Dewetting in Liquid Crystal and Liquid Metal Films. Science 1998;282:916-9.

[127] Reiter G. Dewetting of Highly Elastic Thin Polymer Films. Phys Rev Lett 2001;87:186101/1-4.

[128] Sharma A. Relationship of thin film stability and morphology to macroscopic parameters of wetting in the apolar and polar systems. Langmuir 1993;9:861-9.

[129] Brochard-Wyart F, Di Meglio JM, Quere D, De Gennes PG. Spreading of nonvolatile liquids in a continuum picture. Langmuir 1991;7:335-8.

[130] Xing R, Luo C, Wang Z, Han Y. Dewetting of polymethyl methacrylate on the patterned elastomer substrate by solvent vapor treatment. Polymer 2007;48:357483.

[131] Iii LFP, Russel WB. Electrostatically induced submicron patterning of thin perfect and leaky dielectric films: A generalized linear stability analysis. J Chem Phys 2003; 118:3790-803.

[132] Schäffer E, Thurn-Albrecht T, Russell TP, Steiner U. Electrically induced structure formation and pattern transfer. Nature 2000;403:874-7.

[133] Dickey MD, Raines A, Collister E, Bonnecaze RT, Sreenivasan SV, Willson CG. High-aspect ratio polymeric pillar arrays formed via electrohydrodynamic patterning. J Mater Sci 2007;43:117-22.

[134] Lau CY, Russel WB. Fundamental Limitations on Ordered Electrohydrodynamic Patterning. Macromolecules 2011;44:7746-51. 
[135] Wu N, Russel WB. Micro- and nano-patterns created via electrohydrodynamic instabilities. Nano Today 2009;4:180-92.

[136] Dickey MD, Gupta S, Leach KA, Collister E, Willson CG, Russell TP. Novel 3-D Structures in Polymer Films by Coupling External and Internal Fields. Langmuir 2006;22:4315-8.

[137] Morariu MD, Voicu NE, Schäffer E, Lin Z, Russell TP, Steiner U. Hierarchical structure formation and pattern replication induced by an electric field. Nat Mater 2002;2:48-52.

[138] König T, Goldenberg LM, Kulikovska O, Kulikovsky L, Stumpe J, Santer S. Reversible structuring of photosensitive polymer films by surface plasmon near field radiation. Soft Matter 2011;7:4174-8.

[139] Katzenstein JM, Janes DW, Cushen JD, Hira NB, McGuffin DL, Prisco NA, Ellison CJ. Patterning by Photochemically Directing the Marangoni Effect. ACS Macro Lett 2012;1:1150-4.

[140] Wang Z, Hansen C, Ge Q, Maruf SH, Ahn DU, Qi HJ, Ding Y. Programmable, Pattern-Memorizing Polymer Surface. Adv Mater 2011;23:3669-73.

[141] Tippets CA, Li Q, Fu Y, Donev EU, Zhou J, Turner SA, Jackson AS, Ashby VS, Sheiko SS, Lopez R. Dynamic Optical Gratings Accessed by Reversible Shape Memory. ACS Appl Mater Interfaces 2015;7:14288-93.

[142] Zhao Y, Huang WM, Fu YQ. Formation of micro/nano-scale wrinkling patterns atop shape memory polymers. J Micromechanics Microengineering 2011;21:067007/1-8.

[143] Qiu Y, Park K. Environment-sensitive hydrogels for drug delivery. Adv Drug Deliv Rev 2012;64:49-60.

[144] Peppas NA, Hilt JZ, Khademhosseini A, Langer R. Hydrogels in Biology and Medicine: From Molecular Principles to Bionanotechnology. Adv Mater 2006;18:1345-60.

[145] Tokarev I, Minko S. Stimuli-responsive hydrogel thin films. Soft Matter 2009;5:511-24. 
[146] Peppas NA, Huang Y, Torres-Lugo M, Ward JH, Zhang J. Physicochemical foundations and structural design of hydrogels in medicine and biology. Annu Rev Biomed Eng 2000;2:9-29.

[147] Harris RD, Auletta JT, Motlagh SAM, Lawless MJ, Perri NM, Saxena S, Weiland LM, Waldeck DH, Clark WW, Meyer TY. Chemical and Electrochemical Manipulation of Mechanical Properties in Stimuli-Responsive Copper-CrossLinked Hydrogels. ACS Macro Lett 2013;2:1095-9.

[148] Brannon-Peppas L, Peppas NA. Equilibrium swelling behavior of $\mathrm{pH}$-sensitive hydrogels. Chem Eng Sci 1991;46:715-22.

[149] Matsuo ES, Tanaka T. Patterns in shrinking gels. Nature 1992;358:482-5.

[150] Koetting MC, Peters JT, Steichen SD, Peppas NA. Stimulus-responsive hydrogels: Theory, modern advances, and applications. Mater Sci Eng R Rep 2015;93:1-49.

[151] Aseyev V, Tenhu H, Winnik FM. Non-ionic Thermoresponsive Polymers in Water. Adv Polym Sci 2011;242:29-89.

[152] Ahn S, Kasi RM, Kim SC, Sharma N, Zhou Y. Stimuli-responsive polymer gels. Soft Matter 2008;4:1151-7.

[153] Stuart MAC, Huck WTS, Genzer J, Müller M, Ober C, Stamm M, Sukhorukov GB, Szleifer I, Tsukruk VV, Urban M, Winnik F, Zauscher S, Luzinov I, Minko S. Emerging applications of stimuli-responsive polymer materials. Nat Mater 2010;9:101-13.

[154] Hu Z, Zhang X, Li Y. Synthesis and Application of Modulated Polymer Gels. Science 1995;269:525-7.

[155] Fujishige S, Kubota K, Ando I. Phase transition of aqueous solutions of poly(Nisopropylacrylamide) and poly(N-isopropylmethacrylamide). J Phys Chem 1989;93:3311-3.

[156] Maeda Y, Nakamura T, Ikeda I. Hydration and Phase Behavior of Poly(Nvinylcaprolactam) and Poly(N-vinylpyrrolidone) in Water. Macromolecules 2002;35:217-22.

[157] Hirotsu S, Hirokawa Y, Tanaka T. Volume-phase transitions of ionized Nisopropylacrylamide gels. J Chem Phys 1987;87:1392-5. 
[158] Tanaka T, Sun ST, Nishio I, Swislow G, Shah A. Phase transitions in ionic gels. Ferroelectrics 1980;30:97-97.

[159] Kim P, Zarzar LD, He X, Grinthal A, Aizenberg J. Hydrogel-actuated integrated responsive systems (HAIRS): Moving towards adaptive materials. Curr Opin Solid State Mater Sci 2011;15:236-45.

[160] Stoychev G, Puretskiy N, Ionov L. Self-folding all-polymer thermoresponsive microcapsules. Soft Matter 2011;7:3277-9.

[161] Lee H, Xia C, Fang NX. First jump of microgel\$actuation speed enhancement by elastic instability. Soft Matter 2010;6:4342-5.

[162] Zhang X, Pint CL, Lee MH, Schubert BE, Jamshidi A, Takei K, Ko H, Gillies A, Bardhan R, Urban JJ, Wu M, Fearing R, Javey A. Optically- and ThermallyResponsive Programmable Materials Based on Carbon Nanotube-Hydrogel Polymer Composites. Nano Lett 2011;11:3239-44.

[163] Timoshenko S. Analysis of Bi-metal Thermostats. J Opt Soc Am 1925;11:233-55.

[164] Luo JK, Huang R, He JH, Fu YQ, Flewitt AJ, Spearing SM, Fleck NA, Milne WI. Modelling and fabrication of low operation temperature microcages with a polymer/metal/DLC trilayer structure. Sens Actuators Phys 2006;132:346-53.

[165] Guo W, Li M, Zhou J. Modeling programmable deformation of self-folding allpolymer structures with temperature-sensitive hydrogels. Smart Mater Struct 2013;22:115028/1-6.

[166] Ma Y, Zhang Y, Wu B, Sun W, Li Z, Sun J. Polyelectrolyte Multilayer Films for Building Energetic Walking Devices. Angew Chem Int Ed 2011;50:6254-7.

[167] de Haan LT, Verjans JMN, Broer DJ, Bastiaansen CWM, Schenning APHJ. Humidity-Responsive Liquid Crystalline Polymer Actuators with an Asymmetry in the Molecular Trigger That Bend, Fold, and Curl. J Am Chem Soc 2014; 136:10585-8.

[168] Zhang L, Liang H, Jacob J, Naumov P. Photogated humidity-driven motility. Nat Commun 2015;6:7429/1-11.

[169] Klein Y, Efrati E, Sharon E. Shaping of Elastic Sheets by Prescription of NonEuclidean Metrics. Science 2007;315:1116-20. 
[170] Kim J, Hanna JA, Byun M, Santangelo CD, Hayward RC. Designing Responsive Buckled Surfaces by Halftone Gel Lithography. Science 2012;335:1201-5.

[171] Thérien-Aubin H, Moshe M, Sharon E, Kumacheva E. Shape transformations of soft matter governed by bi-axial stresses. Soft Matter 2015;11:4600-5.

[172] Zhang Y, Ionov L. Reversibly Cross-Linkable Thermoresponsive Self-Folding Hydrogel Films. Langmuir 2015;31:4552-7.

[173] Wei Z, Jia Z, Athas J, Wang C, Raghavan SR, Li T, Nie Z. Hybrid hydrogel sheets that undergo pre-programmed shape transformations. Soft Matter 2014;10:8157-62.

[174] Ye C, Nikolov SV, Calabrese R, Dindar A, Alexeev A, Kippelen B, Kaplan DL, Tsukruk VV. Self-(Un)rolling Biopolymer Microstructures: Rings, Tubules, and Helical Tubules from the Same Material. Angew Chem Int Ed 2015;54:8490-3.

[175] Jeong KU, Jang JH, Kim DY, Nah C, Lee JH, Lee MH, Sun HJ, Wang CL, Cheng SZD, Thomas EL. Three-dimensional actuators transformed from the programmed two-dimensional structures via bending, twisting and folding mechanisms. J Mater Chem 2011;21:6824-30.

[176] Wu ZL, Moshe M, Greener J, Therien-Aubin H, Nie Z, Sharon E, Kumacheva E. Three-dimensional shape transformations of hydrogel sheets induced by smallscale modulation of internal stresses. Nat Commun 2013;4:1586/1-7.

[177] Maeda S, Hara Y, Sakai T, Yoshida R, Hashimoto S. Self-Walking Gel. Adv Mater 2007;19:3480-4.

[178] Jamal M, Zarafshar AM, Gracias DH. Differentially photo-crosslinked polymers enable self-assembling microfluidics. Nat Commun 2011;2:527/1-6.

[179] Kim J, Hanna JA, Hayward RC, Santangelo CD. Thermally responsive rolling of thin gel strips with discrete variations in swelling. Soft Matter 2012;8:2375-81.

[180] Huang G, Mei Y, Thurmer DJ, Coric E, Schmidt OG. Rolled-up transparent microtubes as two-dimensionally confined culture scaffolds of individual yeast cells. Lab Chip 2009;9:263-8.

[181] Liu Y, Takafuji M, Ihara H, Zhu M, Yang M, Gu K, Guo W. Programmable responsive shaping behavior induced by visible multi-dimensional gradients of magnetic nanoparticles. Soft Matter 2012;8:3295-9. 
[182] Liu F, Urban MW. Recent advances and challenges in designing stimuliresponsive polymers. Prog Polym Sci 2010;35:3-23.

[183] Hauser AW, Evans AA, Na JH, Hayward RC. Photothermally Reprogrammable Buckling of Nanocomposite Gel Sheets. Angew Chem Int Ed 2015;54:5434-7.

[184] Tanaka T, Nishio I, Sun ST, Ueno-Nishio S. Collapse of Gels in an Electric Field. Science 1982;218:467-9.

[185] Jager EWH. Microrobots for Micrometer-Size Objects in Aqueous Media: Potential Tools for Single-Cell Manipulation. Science 2000;288:2335-8.

[186] Smela E, Inganas O, Lundstrom I. Controlled Folding of Micrometer-Size Structures. Science 1995;268:1735-8.

[187] Palleau E, Morales D, Dickey MD, Velev OD. Reversible patterning and actuation of hydrogels by electrically assisted ionoprinting. Nat Commun 2013;4:2257/1-7.

[188] Lee BP, Konst S. Novel Hydrogel Actuator Inspired by Reversible Mussel Adhesive Protein Chemistry. Adv Mater 2014;26:3415-9.

[189] Kabiri K, Azizi A, Zohuriaan-Mehr MJ, Marandi GB, Bouhendi H. Poly(acrylic acid-sodium styrene sulfonate) organogels: Preparation, characterization, and alcohol superabsorbency. J Appl Polym Sci 2011;119:2759-69.

[190] Ceylan D, Okay O. Macroporous Polyisobutylene Gels: A Novel Tough Organogel with Superfast Responsivity. Macromolecules 2007;40:8742-9.

[191] Vintiloiu A, Leroux JC. Organogels and their use in drug delivery - A review. J Controlled Release 2008;125:179-92.

[192] Lee JN, Park C, Whitesides GM. Solvent Compatibility of Poly(dimethylsiloxane)-Based Microfluidic Devices. Anal Chem 2003;75:654454.

[193] Stoychev G, Zakharchenko S, Turcaud S, Dunlop JWC, Ionov L. ShapeProgrammed Folding of Stimuli-Responsive Polymer Bilayers. ACS Nano 2012;6:3925-34.

[194] Sun Z, Huang Q, He T, Li Z, Zhang Y, Yi L. Multistimuli-Responsive Supramolecular Gels: Design Rationale, Recent Advances, and Perspectives. ChemPhysChem 2014;15:2421-30. 
[195] Zakharchenko S, Puretskiy N, Stoychev G, Stamm M, Ionov L. Temperature controlled encapsulation and release using partially biodegradable thermomagneto-sensitive self-rolling tubes. Soft Matter 2010;6:2633-6.

[196] Guan JJ, He HY, Hansford DJ, Lee LJ. Self-folding of three-dimensional hydrogel microstructures. J Phys Chem B 2005;109:23134-7.

[197] Martinez RV, Fish CR, Chen X, Whitesides GM. Elastomeric Origami: Programmable Paper-Elastomer Composites as Pneumatic Actuators. Adv Funct Mater 2012;22:1376-84.

[198] Lu YW, Kim CJ. Microhand for biological applications. Appl Phys Lett 2006;89:164101/1-3.

[199] Kusuda S, Sawano S, Konishi S. Fluid-resistive bending sensor having perfect compatibility with flexible pneumatic balloon actuator. IEEE (MEMS) 2007. p. 615-8.

[200] Tolley MT, Shepherd RF, Karpelson M, Bartlett NW, Galloway KC, Wehner M, Nunes R, Whitesides GM, Wood RJ. An untethered jumping soft robot. IEEE (IROS) 2014. p. 561-6.

[201] Shepherd RF, Stokes AA, Freake J, Barber J, Snyder PW, Mazzeo AD, Cademartiri L, Morin SA, Whitesides GM. Using Explosions to Power a Soft Robot. Angew Chem Int Ed 2013;52:2892-6.

[202] van Oosten CL, Bastiaansen CWM, Broer DJ. Printed artificial cilia from liquidcrystal network actuators modularly driven by light. Nat Mater 2009;8:677-82.

[203] Wie JJ, Lee KM, Smith ML, Vaia RA, White TJ. Torsional mechanical responses in azobenzene functionalized liquid crystalline polymer networks. Soft Matter 2013;9:9303-10.

[204] Ohm C, Brehmer M, Zentel R. Liquid Crystalline Elastomers as Actuators and Sensors. Adv Mater 2010;22:3366-87.

[205] Ikeda T, Nakano M, Yu Y, Tsutsumi O, Kanazawa A. Anisotropic Bending and Unbending Behavior of Azobenzene Liquid-Crystalline Gels by Light Exposure. Adv Mater 2003;15:201-5. 
[206] White TJ, Serak SV, Tabiryan NV, Vaia RA, Bunning TJ. Polarization-controlled, photodriven bending in monodomain liquid crystal elastomer cantilevers. J Mater Chem 2009;19:1080-5.

[207] Liu D, Bastiaansen CWM, den Toonder JMJ, Broer DJ. Light-Induced Formation of Dynamic and Permanent Surface Topologies in Chiral-Nematic Polymer Networks. Macromolecules 2012;45:8005-12.

[208] Das S, Varghese S, Kumar NSS. Butadiene-Based Photoresponsive Soft Materials. Langmuir 2010;26:1598-609.

[209] Ware TH, McConney ME, Wie JJ, Tondiglia VP, White TJ. Voxelated liquid crystal elastomers. Science 2015;347:982-4.

[210] Verduzco R. Shape-shifting liquid crystals. Science 2015;347:949-50.

[211] Ware TH, White TJ. Programmed liquid crystal elastomers with tunable actuation strain. Polym Chem 2015;6:4835-44.

[212] Collings PJ, Patel JS, editors. Handbook of liquid crystal research. New York: Oxford University Press 1997. 600 pp.

[213] Fleischmann EK, Zentel R. Liquid-Crystalline Ordering as a Concept in Materials Science: From Semiconductors to Stimuli-Responsive Devices. Angew Chem Int Ed 2013;52:8810-27.

[214] Agrawal A, Yun T, Pesek SL, Chapman WG, Verduzco R. Shape-responsive liquid crystal elastomer bilayers. Soft Matter 2014;10:1411-5.

[215] Liu D, Broer DJ. Liquid Crystal Polymer Networks: Preparation, Properties, and Applications of Films with Patterned Molecular Alignment. Langmuir 2014;30:13499-509.

[216] Tajbakhsh AR, Terentjev EM. Spontaneous thermal expansion of nematic elastomers. Eur Phys J E 2001;6:181-8.

[217] Thomsen DL, Keller P, Naciri J, Pink R, Jeon H, Shenoy D, Ratna BR. Liquid Crystal Elastomers with Mechanical Properties of a Muscle. Macromolecules 2001;34:5868-75.

[218] Lee KM, Koerner H, Vaia RA, Bunning TJ, White TJ. Light-activated shape memory of glassy, azobenzene liquid crystalline polymer networks. Soft Matter 2011;7:4318-24. 
[219] Lendlein A, Jiang H, Juenger O, Langer R. Light-induced shape-memory polymers. Nature 2005;434:879-82.

[220] Jiang HY, Kelch S, Lendlein A. Polymers Move in Response to Light. Adv Mater 2006; 18:1471-5.

[221] Chatani S, Kloxin CJ, Bowman CN. The power of light in polymer science: photochemical processes to manipulate polymer formation, structure, and properties. Polym Chem 2014;5:2187-201.

[222] Habault D, Zhang H, Zhao Y. Light-triggered self-healing and shape-memory polymers. Chem Soc Rev 2013;42:7244-56.

[223] Long KN, Scott TF, Qi HJ, Bowman CN, Dunn ML. Photomechanics of lightactivated polymers. J Mech Phys Solids 2009;57:1103-21.

[224] Mu X, Sowan N, Tumbic JA, Bowman CN, Mather PT, Qi HJ. Photo-induced bending in a light-activated polymer laminated composite. Soft Matter 2015;11:2673-82.

[225] Ma J, Mu X, Bowman CN, Sun Y, Dunn ML, Qi HJ, Fang D. A photoviscoplastic model for photoactivated covalent adaptive networks. J Mech Phys Solids 2014;70:84-103.

[226] Yu Y, Nakano M, Ikeda T. Photomechanics: Directed bending of a polymer film by light. Nature 2003;425:145-145.

[227] White TJ, Tabiryan NV, Serak SV, Hrozhyk UA, Tondiglia VP, Koerner H, Vaia RA, Bunning TJ. A high frequency photodriven polymer oscillator. Soft Matter 2008;4:1796-8.

[228] Barrett CJ, Mamiya J, Yager KG, Ikeda T. Photo-mechanical effects in azobenzene-containing soft materials. Soft Matter 2007;3:1249-61.

[229] Kopyshev A, Galvin CJ, Genzer J, Lomadze N, Santer S. Opto-Mechanical Scission of Polymer Chains in Photosensitive Diblock-Copolymer Brushes. Langmuir 2013;29:13967-74.

[230] Podgórski M, Nair DP, Chatani S, Berg G, Bowman CN. Programmable Mechanically Assisted Geometric Deformations of Glassy Two-Stage Reactive Polymeric Materials. ACS Appl Mater Interfaces 2014;6:6111-9. 
[231] Bar-Cohen Y, editor. Electroactive polymer (EAP) actuators as artificial muscles: reality, potential, and challenges. Bellingham WA: SPIE Press, 2001. 671 pp.

[232] Brochu P, Pei Q. Advances in Dielectric Elastomers for Actuators and Artificial Muscles. Macromol Rapid Commun 2010;31:10-36.

[233] Bauer S, Bauer-Gogonea S, Graz I, Kaltenbrunner M, Keplinger C, Schwödiauer R. 25th Anniversary Article: A Soft Future: From Robots and Sensor Skin to Energy Harvesters. Adv Mater 2014;26:149-62.

[234] Biggs J, Danielmeier K, Hitzbleck J, Krause J, Kridl T, Nowak S, Orselli E, Quan X, Schapeler D, Sutherland W, Wagner J. Electroactive Polymers: Developments of and Perspectives for Dielectric Elastomers. Angew Chem Int Ed 2013;52:940921.

[235] Ahmed S, McGough K, Ounaies Z, Frecker M. Origami-Inspired Folding and Unfolding of Structures: Fundamental Investigations of Dielectric ElastomerBased Active Materials. ASME Proc. 2013. p. V001T01A029/1-6.

[236] Anderson IA, Gisby TA, McKay TG, O’Brien BM, Calius EP. Multi-functional dielectric elastomer artificial muscles for soft and smart machines. J Appl Phys 2012;112:041101/1-20.

[237] Ambrosy A, Holdik K. Piezoelectric PVDF films as ultrasonic transducers. J Phys E 1984;17:856-9.

[238] Shirinov AV, Schomburg WK. Pressure sensor from a PVDF film. Sens Actuators Phys 2008;142:48-55.

[239] Carta F, Hsu YJ, Sarik J, Kymissis I. Bimorph actuator with monolithically integrated CMOS OFET control. Org Electron 2013;14:286-90.

[240] Hsu YJ, Jia Z, Kymissis I. A Locally Amplified Strain Sensor Based on a Piezoelectric Polymer and Organic Field-Effect Transistors. IEEE Trans Electron Devices 2011;58:910-7.

[241] Khodaparast P, Ounaies Z. On the impact of functionalization and thermal treatment on dielectric behavior of low content $\mathrm{TiO}_{2}$ PVDF nanocomposites. IEEE Trans Dielectr Electr Insul 2013;20:166-7.

[242] Jaffe B. Piezoelectric Ceramics. Burlington: Elsevier Science 1971. 328 pp. 
[243] Pak YE. Linear electro-elastic fracture mechanics of piezoelectric materials. Int J Fract 1992;54:79-100.

[244] Hagood NW, von Flotow A. Damping of structural vibrations with piezoelectric materials and passive electrical networks. J Sound Vib 1991;146:243-68.

[245] Luzinov I, Minko S, Tsukruk VV. Responsive brush layers: from tailored gradients to reversibly assembled nanoparticles. Soft Matter 2008;4:714-25.

[246] Wu T, Efimenko K, Genzer J. Combinatorial Study of the Mushroom-to-Brush Crossover in Surface Anchored Polyacrylamide. J Am Chem Soc 2002;124:93945.

[247] Motornov M, Sheparovych R, Lupitskyy R, MacWilliams E, Hoy O, Luzinov I, Minko S. Stimuli-Responsive Colloidal Systems from Mixed Brush-Coated Nanoparticles. Adv Funct Mater 2007;17:2307-14.

[248] Wu T, Efimenko K, Vlček P, Šubr V, Genzer J. Formation and Properties of Anchored Polymers with a Gradual Variation of Grafting Densities on Flat Substrates. Macromolecules 2003;36:2448-53.

[249] Sheparovych R, Motornov M, Minko S. Adapting Low-Adhesive Thin Films from Mixed Polymer Brushes. Langmuir 2008;24:13828-32.

[250] Sheparovych R, Motornov M, Minko S. Low Adhesive Surfaces that Adapt to Changing Environments. Adv Mater 2009;21:1840-4.

[251] Brittain ST, Schueller OJA, Wu H, Whitesides S, Whitesides GM. Microorigami: Fabrication of Small, Three-Dimensional, Metallic Structures. J Phys Chem B 2001;105:347-50.

[252] Pickett GT. Self-folding origami membranes. Europhys Lett EPL 2007;78:48003/1-6.

[253] Mahadevan L. Self-Organized Origami. Science 2005;307:1740-1740.

[254] Felton SM, Tolley MT, Shin B, Onal CD, Demaine ED, Rus D, Wood RJ. Selffolding with shape memory composites. Soft Matter 2013;9:7688-94.

[255] Fernandes R, Gracias DH. Self-folding polymeric containers for encapsulation and delivery of drugs. Adv Drug Deliv Rev 2012;64:1579-89.

[256] Stoychev G, Turcaud S, Dunlop JWC, Ionov L. Hierarchical Multi-Step Folding of Polymer Bilayers. Adv Funct Mater 2013;23:2295-300. 
[257] Langer R, Tirrell DA. Designing materials for biology and medicine. Nature 2004;428:487-92.

[258] Feinberg AW, Feigel A, Shevkoplyas SS, Sheehy S, Whitesides GM, Parker KK. Muscular Thin Films for Building Actuators and Powering Devices. Science 2007;317:1366-70.

[259] Xi J, Schmidt JJ, Montemagno CD. Self-assembled microdevices driven by muscle. Nat Mater 2005;4:180-4.

[260] Marras AE, Zhou L, Su HJ, Castro CE. Programmable motion of DNA origami mechanisms. Proc Natl Acad Sci 2015;112:713-8.

[261] Studart AR, Erb RM. Bioinspired materials that self-shape through programmed microstructures. Soft Matter 2014;10:1284-94.

[262] Studart AR. Biologically Inspired Dynamic Material Systems. Angew Chem Int Ed 2015;54:3400-16.

[263] Yao L, Ou J, Cheng CY, Steiner H, Wang W, Wang G, Ishii H. BioLogic: Natto Cells as Nanoactuators for Shape Changing Interfaces. Proc ACM Confr 2015. p. 1-10.

[264] Ou J, Yao L, Silva C, Wang W, Ishii H. BioPrint: an automatic deposition system for bacteria spore actuators. Proc ACM Symp 2014. p. 121-2.

[265] Laflin KE, Morris CJ, Muqeem T, Gracias DH. Laser triggered sequential folding of microstructures. Appl Phys Lett 2012;101:131901/1-4.

[266] Liu Y, Miskiewicz M, Escuti MJ, Genzer J, Dickey MD. Three-dimensional folding of pre-strained polymer sheets via absorption of laser light. J Appl Phys 2014;115:204911/1-6.

[267] Ebefors T, Kälvesten E, Stemme G. Dynamic actuation of polyimide V-groove joints by electrical heating. Sens Actuators Phys 1998;67:199-204.

[268] Suzuki K, Yamada H, Miura H, Takanobu H. Self-assembly of three dimensional micro mechanisms using thermal shrinkage of polyimide. Microsyst Technol 2006;13:1047-53.

[269] Piqué A, Mathews S, Birnbaum A, Charipar N. Microfabricating 3D structures by laser origami. SPIE Newsroom 2011 DOI: 10.1117/2.1201111.003952. 
[270] Azam A, Laflin KE, Jamal M, Fernandes R, Gracias DH. Self-folding micropatterned polymeric containers. Biomed Microdevices 2011;13:51-8.

[271] Cho JH, Azam A, Gracias DH. Three Dimensional Nanofabrication Using Surface Forces. Langmuir 2010;26:16534-9.

[272] Yoon C, Xiao R, Park J, Cha J, Nguyen TD, Gracias DH. Functional stimuli responsive hydrogel devices by self-folding. Smart Mater Struct 2014;23:094008/1-10.

[273] Tolley MT, Felton SM, Miyashita S, Aukes D, Rus D, Wood RJ. Self-folding origami: shape memory composites activated by uniform heating. Smart Mater Struct 2014;23:094006/1-9.

[274] An B, Miyashita S, Tolley MT, Aukes DM, Meeker L, Demaine ED, Demaine ML, Wood RJ, Rus D. An end-to-end approach to making self-folded 3D surface shapes by uniform heating. IEEE (ICRA) 2014. p. 1466-73.

[275] Felton SM, Tolley MT, Wood RJ. Mechanically programmed self-folding at the millimeter scale. IEEE (CASE) 2014. p. 1232-7.

[276] Miyashita S, Meeker L, Tolley MT, Wood RJ, Rus D. Self-folding miniature elastic electric devices. Smart Mater Struct 2014;23:094005/1-9.

[277] Felton S, Tolley M, Demaine E, Rus D, Wood R. A method for building selffolding machines. Science 2014;345:644-6.

[278] Ahmed S, Lauff C, Crivaro A, McGough K, Sheridan R, Frecker M, von Lockett P, Ounaies Z, Simpson T, Lien JM, Strzelec R. Multi-Field Responsive Origami Structures: Preliminary Modeling and Experiments. ASME Proc. 2013. p. V06BT07A028.

[279] Na JH, Evans AA, Bae J, Chiappelli MC, Santangelo CD, Lang RJ, Hull TC, Hayward RC. Programming Reversibly Self-Folding Origami with Micropatterned Photo-Crosslinkable Polymer Trilayers. Adv Mater 2015;27:7985.

[280] Leng J, Lan X, Liu Y, Du S. Shape-memory polymers and their composites: Stimulus methods and applications. Prog Mater Sci 2011;56:1077-135.

[281] Lendlein A. Biodegradable, Elastic Shape-Memory Polymers for Potential Biomedical Applications. Science 2002;296:1673-6. 
[282] Behl M, Razzaq MY, Lendlein A. Multifunctional Shape-Memory Polymers. Adv Mater 2010;22:3388-410.

[283] Cuevas JM, Rubio R, Germán L, Laza JM, Vilas JL, Rodriguez M, León LM. Triple-shape memory effect of covalently crosslinked polyalkenamer based semicrystalline polymer blends. Soft Matter 2012;8:4928-35.

[284] Julich-Gruner KK, Löwenberg C, Neffe AT, Behl M, Lendlein A. Recent Trends in the Chemistry of Shape-Memory Polymers. Macromol Chem Phys 2013;214:527-36.

[285] Small W, Metzger MF, Wilson TS, Maitland DJ. Laser-activated shape memory polymer microactuator for thrombus removal following ischemic stroke: preliminary in vitro analysis. IEEE J Sel Top Quantum Electron 2005;11:892-901.

[286] Yakacki CM, Shandas R, Lanning C, Rech B, Eckstein A, Gall K. Unconstrained recovery characterization of shape-memory polymer networks for cardiovascular applications. Biomaterials 2007;28:2255-63.

[287] Lendlein A, Kelch S. Shape-Memory Polymers. Angew Chem Int Ed 2002;41:2034-57.

[288] Mavroidis C, Pfeiffer C, Mosley M. Conventional Actuators, Shape Memory Alloys, And Electrorheological Fluids. In: Bar-Cohen Y, editor. Autom Miniat Robot Sens Non-Destr Test Eval. Columbus, OH: American Society for Nondestructive Testing, 1999. p. 5.1-5.26.

[289] Wei ZG, Sandstroröm R, Miyazaki S. Shape-memory materials and hybrid composites for smart systems: Part I Shape-memory materials. J Mater Sci 1998;33:3743-62.

[290] Rousseau IA, Mather PT. Shape Memory Effect Exhibited by Smectic-C Liquid Crystalline Elastomers. J Am Chem Soc 2003;125:15300-1.

[291] de Haan LT, Gimenez-Pinto V, Konya A, Nguyen TS, Verjans JMN, SánchezSomolinos C, Selinger JV, Selinger RLB, Broer DJ, Schenning APHJ. Accordionlike Actuators of Multiple 3D Patterned Liquid Crystal Polymer Films. Adv Funct Mater 2014;24:1251-8. 
[292] Mingallon M, Ramaswamy S. Bio-Inspired Self-Actuating Composite Materials. In: Hu N, editor. Composites and Their Applications. Rijeka: InTech. 2012. p. 355-374.

[293] Cardona D. Shape Memory And Iron Palladium Alloys. http://taboodada.wordpress.com/2011/03/31/41/ 2014. 3 pp. Accessed December 2014.

[294] Liu C, Qin H, Mather PT. Review of progress in shape-memory polymers. J Mater Chem 2007; 17:1543-58.

[295] Ratna D, Karger-Kocsis J. Recent advances in shape memory polymers and composites: a review. J Mater Sci 2008;43:254-69.

[296] Behl M, Zotzmann J, Lendlein A. Shape-Memory Polymers and Shape-Changing Polymers. Adv Polym Sci 2009;226:1-40.

[297] Otsuka K, Ren X. Recent developments in the research of shape memory alloys. Intermetallics 1999;7:511-28.

[298] Sun L, Huang WM, Ding Z, Zhao Y, Wang CC, Purnawali H, Tang C. Stimulusresponsive shape memory materials: A review. Mater Des 2012;33:577-640.

[299] Huang WM, Lu HB, Zhao Y, Ding Z, Wang CC, Zhang JL, Sun L, Fu J, Gao XY. Instability/collapse of polymeric materials and their structures in stimulus-induced shape/surface morphology switching. Mater Des 2014;59:176-92.

[300] Peraza Hernandez EA, Hu S, HW Kung, Hartl D, Akleman E. Towards building smart self-folding structures. Comput Graph n.d. 2013;37:730-42.

[301] Lee AP, Ciarlo DR, Krulevitch PA, Lehew S, Trevino J, Northrup MA. A practical microgripper by fine alignment, eutectic bonding and SMA actuation. Sens Actuators Phys 1996;54:755-9.

[302] Peraza-Hernandez EA, Hartl DJ, Malak Jr RJ. Design and numerical analysis of an SMA mesh-based self-folding sheet. Smart Mater Struct 2013;22:094008/1-17.

[303] Peraza-Hernandez E, Hartl D, Galvan E, Malak R. Design and Optimization of a Shape Memory Alloy-Based Self-Folding Sheet. J Mech Des 2013;135:111007/111. 
[304] Oehler SD, Hartl DJ, Lopez R, Malak RJ, Lagoudas DC. Design optimization and uncertainty analysis of SMA morphing structures. Smart Mater Struct 2012;21:094016/1-16.

[305] Paik JK, Wood RJ. A bidirectional shape memory alloy folding actuator. Smart Mater Struct 2012;21:065013/1-8.

[306] Hu J, Zhu Y, Huang H, Lu J. Recent advances in shape-memory polymers: Structure, mechanism, functionality, modeling and applications. Prog Polym Sci 2012;37:1720-63.

[307] Behl M, Lendlein A. Shape-memory polymers. Mater Today 2007;10:20-8.

[308] Lendlein A, Sauter T. Shape-Memory Effect in Polymers. Macromol Chem Phys 2013;214:1175-7.

[309] Mather PT, Luo XF, Rousseau IA. Shape Memory Polymer Research. Annu Rev Mater Res 2009;39:445-71.

[310] Meng H, Li G. Reversible switching transitions of stimuli-responsive shape changing polymers. J Mater Chem A 2013;1:7838-65.

[311] Leng J, Du S. Shape-memory polymers and multifunctional composites. Boca Raton: Taylor \& Francis, 2010. 373 pp.

[312] Meng H, Li G. A review of stimuli-responsive shape memory polymer composites. Polymer 2013;54:2199-221.

[313] Berg GJ, McBride MK, Wang C, Bowman CN. New directions in the chemistry of shape memory polymers. Polymer 2014;55:5849-72.

[314] Hager MD, Bode S, Weber C, Schubert US. Shape memory polymers: Past, present and future developments. Prog Polym Sci 2015 DOI:

10.1016/j.progpolymsci.2015.04.002, in press.

[315] Zhao Q, Qi HJ, Xie T. Recent progress in shape memory polymer: New behavior, enabling materials, and mechanistic understanding. Prog Polym Sci 2015 DOI: 10.1016/j.progpolymsci.2015.04.001, in press.

[316] Kunzelman J, Chung T, Mather PT, Weder C. Shape memory polymers with built-in threshold temperature sensors. J Mater Chem 2008;18:1082-6.

[317] Xie T. Recent advances in polymer shape memory. Polymer 2011;52:4985-5000.

[318] Xie T. Tunable polymer multi-shape memory effect. Nature 2010;464:267-70. 
[319] Luo X, Mather PT. Triple-Shape Polymeric Composites (TSPCs). Adv Funct Mater 2010;20:2649-56.

[320] Torbati AH, Nejad HB, Ponce M, Sutton JP, Mather PT. Properties of triple shape memory composites prepared via polymerization-induced phase separation. Soft Matter 2014;10:3112-21.

[321] He Z, Satarkar N, Xie T, Cheng YT, Hilt JZ. Remote Controlled Multishape Polymer Nanocomposites with Selective Radiofrequency Actuations. Adv Mater 2011;23:3192-6.

[322] Felton SM, Tolley MT, Onal CD, Rus D, Wood RJ. Robot self-assembly by folding: A printed inchworm robot. IEEE (ICRA) 2013. p. 277-82.

[323] Sun X, Felton SM, Niiyama R, Wood RJ, Kim S. Self-folding and self-actuating robots: A pneumatic approach. IEEE (ICRA) 2015. p. 3160-5.

[324] Liu Y, Boyles JK, Genzer J, Dickey MD. Self-folding of polymer sheets using local light absorption. Soft Matter 2012;8:1764-9.

[325] Liu Y, Mailen R, Zhu Y, Dickey MD, Genzer J. Simple geometric model to describe self-folding of polymer sheets. Phys Rev E 2014;89:042601/1-8.

[326] Henry CP, McKnight GP, Enke A, Bortolin R, Joshi S. 3D FEA simulation of segmented reinforcement variable stiffness composites. Proc SPIE 2008;6929:69290X/1-12.

[327] Mcknight G, Doty R, Keefe A, Herrera G, Henry C. Segmented Reinforcement Variable Stiffness Materials for Reconfigurable Surfaces. J Intell Mater Syst Struct 2010;21:1783-93.

[328] Tolman SS, Delimont IL, Howell LL, Fullwood DT. Material selection for elastic energy absorption in origami-inspired compliant corrugations. Smart Mater Struct 2014;23:094010/1-9.

[329] Chung T, Romo-Uribe A, Mather PT. Two-Way Reversible Shape Memory in a Semicrystalline Network. Macromolecules 2008;41:184-92.

[330] Chen S, Hu J, Zhuo H. Properties and mechanism of two-way shape memory polyurethane composites. Compos Sci Technol 2010;70:1437-43.

[331] Sellinger AT, Wang DH, Tan LS, Vaia RA. Electrothermal Polymer Nanocomposite Actuators. Adv Mater 2010;22:3430-5. 
[332] Westbrook KK, Mather PT, Parakh V, Dunn ML, Ge Q, Lee BM, Qi HJ. Twoway reversible shape memory effects in a free-standing polymer composite. Smart Mater Struct 2011;20:065010/1-9.

[333] Tamagawa $\mathrm{H}$. Thermo-responsive two-way shape changeable polymeric laminate. Mater Lett 2010;64:749-51.

[334] Behl M, Kratz K, Zotzmann J, Nöchel U, Lendlein A. Reversible Bidirectional Shape-Memory Polymers. Adv Mater 2013;25:4466-9.

[335] Zotzmann J, Behl M, Hofmann D, Lendlein A. Reversible Triple-Shape Effect of Polymer Networks Containing Polypentadecalactone- and Poly( $\varepsilon$-caprolactone)Segments. Adv Mater 2010;22:3424-9.

[336] Li J, Rodgers WR, Xie T. Semi-crystalline two-way shape memory elastomer. Polymer 2011;52:5320-5.

[337] Zhou J, Turner SA, Brosnan SM, Li Q, Carrillo JMY, Nykypanchuk D, Gang O, Ashby VS, Dobrynin AV, Sheiko SS. Shapeshifting: Reversible Shape Memory in Semicrystalline Elastomers. Macromolecules 2014;47:1768-76.

[338] Yang X, Wang L, Wang W, Chen H, Yang G, Zhou S. Triple Shape Memory Effect of Star-Shaped Polyurethane. ACS Appl Mater Interfaces 2014;6:6545-54.

[339] Turner SA, Zhou J, Sheiko SS, Ashby VS. Switchable Micropatterned Surface Topographies Mediated by Reversible Shape Memory. ACS Appl Mater Interfaces 2014;6:8017-21.

[340] Pandini S, Passera S, Messori M, Paderni K, Toselli M, Gianoncelli A, Bontempi E, Riccò T. Two-way reversible shape memory behaviour of crosslinked poly $(\varepsilon-$ caprolactone). Polymer 2012;53:1915-24.

[341] PPandini S, Baldi F, Paderni K, Messori M, Toselli M, Pilati F, Gianoncelli A, Brisotto M, Bontempi E, Riccò T. One-way and two-way shape memory behaviour of semi-crystalline networks based on sol-gel cross-linked poly $(\varepsilon-$ caprolactone). Polymer 2013;54:4253-65.

[342] Baker RM, Henderson JH, Mather PT. Shape memory poly( $\varepsilon$-caprolactone)-copoly(ethylene glycol) foams with body temperature triggering and two-way actuation. J Mater Chem B 2013;1:4916-20. 
[343] Ebara M, Uto K, Idota N, Hoffman JM, Aoyagi T. Rewritable and shape-memory soft matter with dynamically tunable microchannel geometry in a biological temperature range. Soft Matter 2013;9:3074-80.

[344] Bothe M, Pretsch T. Bidirectional actuation of a thermoplastic polyurethane elastomer. J Mater Chem A 2013;1:14491-7.

[345] Zhou J, Li Q, Turner SA, Ashby VS, Sheiko SS. Isothermal programming of triple shape memory. Polymer 2015;72:464-70.

[346] Lang RJ. A Computational Algorithm for Origami Design. Proc Twelfth Annu Symp Comput Geom. New York, NY: ACM Press, 1996. p. 98-105.

[347] Connelly R, Demaine ED, Rote G. Straightening polygonal arcs and convexifying polygonal cycles. IEEE (Comput Sci) 2000. p. 432-42.

[348] Demaine ED, Demaine ML, Eppstein D, Frederickson GN, Friedman E. Hinged dissection of polyominoes and polyforms. Comput Geom 2005;31:237-62.

[349] Silverberg JL, Na JH, Evans AA, Liu B, Hull TC, Santangelo CD, Lang RJ, Hayward RC, Cohen I. Origami structures with a critical transition to bistability arising from hidden degrees of freedom. Nat Mater 2015;14:389-93.

[350] Evans AA, Silverberg JL, Santangelo CD. Lattice Mechanics of Origami Tessellations. Phys Rev E 2015;92:013205/1-12.

[351] Rao A, Tawfick S, Shlian M, Hart AJ. Fold Mechanics of Natural and Synthetic Origami Papers. ASME Proc. 203. p. V06BT07A049.

[352] Sussman DM, Cho Y, Castle T, Gong X, Jung E, Yang S, Kamien RD. Algorithmic lattice kirigami: A route to pluripotent materials. Proc Natl Acad Sci 2015;112:7449-53.

[353] Castle T, Cho Y, Gong X, Jung E, Sussman DM, Yang S, Kamien RD. Making the Cut: Lattice Kirigami Rules. Phys Rev Lett 2014;113:245502/1-5.

[354] Howell LL. Compliant mechanisms. New York: John Wiley \& Sons Inc, 2001. $459 \mathrm{pp}$.

[355] Greenberg HC, Gong ML, Magleby SP, Howell LL. Identifying links between origami and compliant mechanisms. Mech Sci 2011;2:217-25. 
[356] Frecker MI, Ananthasuresh GK, Nishiwaki S, Kikuchi N, Kota S. Topological Synthesis of Compliant Mechanisms Using Multi-Criteria Optimization. J Mech Des 1997;119:238-45.

[357] Delimont IL, Magleby SP, Howell LL. Evaluating Compliant Hinge Geometries for Origami-Inspired Mechanisms. J Mech Robot 2015;7:011009/1-8.

[358] Homer ER, Harris MB, Zirbel SA, Kolodziejska JA, Kozachkov H, Trease BP, Borgonia JPC, Agnes GS, Howell LL, Hofmann DC. New Methods for Developing and Manufacturing Compliant Mechanisms Utilizing Bulk Metallic Glass: New Methods for Developing and Manufacturing Compliant Mechanisms. Adv Eng Mater 2014;16:850-6.

[359] Aukes DM, Wood RJ. PopupCAD: a tool for automated design, fabrication, and analysis of laminate devices. Proc SPIE 2015;9467:94671B.

[360] Joo JJ, Sanders B, Johnson T, Frecker MI. Optimal actuator location within a morphing wing scissor mechanism configuration. Proc SPIE 2006 6166: 24-35.

[361] Santer M, Pellegrino S. Concept and Design of a Multistable Plate Structure. J Mech Des 2011;133:081001/1-7.

[362] Fuchi K, Buskohl PR, Ware T, Vaia RA, White TJ, Reich GW, Joo JJ. Inverse Design of LCN Films for Origami Applications Using Topology Optimization. ASME Proc. 2014. p. V001T01A011/1-7.

[363] Luo JK, He JH, Fu YQ, Flewitt AJ, Spearing SM, Fleck NA, Milne WI. Fabrication and characterization of diamond-like carbon/Ni bimorph normally closed microcages. J Micromechanics Microengineering 2005;15:1406-13.

[364] Malachowski K, Breger J, Kwag HR, Wang MO, Fisher JP, Selaru FM, Gracias DH. Stimuli-Responsive Theragrippers for Chemomechanical Controlled Release. Angew Chem Int Ed 2014;53:1-6.

[365] Fusco S, Sakar MS, Kennedy S, Peters C, Bottani R, Starsich F, Mao A, Sotiriou GA, Pané S, Pratsinis SE, Mooney D, Nelson BJ. An Integrated Microrobotic Platform for On-Demand, Targeted Therapeutic Interventions. Adv Mater 2013;26:952-7. 
[366] de Leon A, Barnes AC, Thomas P, O'Donnell J, Zorman CA, Advincula RC. Transfer Printing of Self-Folding Polymer-Metal Bilayer Particles. ACS Appl Mater Interfaces 2014;6:22695-700.

[367] Deng T, Yoon C, Jin Q, Li M, Liu Z, Gracias DH. Self-folding graphene-polymer bilayers. Appl Phys Lett 2015;106:203108/1-4.

[368] Zhang X, Yu Z, Wang C, Zarrouk D, Seo JWT, Cheng JC, Buchan AD, Takei K, Zhao Y, Ager JW, Zhang J, Hettick M, Hersam MC, Pisano AP, Fearing RS, Javey A. Photoactuators and motors based on carbon nanotubes with selective chirality distributions. Nat Commun 2014;5:2983/1-8.

[369] Tu H, Jiang H, Yu H, Xu Y. Hybrid silicon-polymer platform for self-locking and self-deploying origami. Appl Phys Lett 2013;103:241902/1-4.

[370] Ma C, Li T, Zhao Q, Yang X, Wu J, Luo Y, Xie T. Supramolecular Lego Assembly Towards Three-Dimensional Multi-Responsive Hydrogels. Adv Mater 2014;26:5665-9.

[371] Zhou F, Shu W, Welland ME, Huck WTS. Highly Reversible and Multi-Stage Cantilever Actuation Driven by Polyelectrolyte Brushes. J Am Chem Soc 2006;128:5326-7.

[372] Morales D, Palleau E, Dickey MD, Velev OD. Electro-actuated Hydrogel Walkers with Dual Responsive Legs. Soft Matter 2014;10:1337-48.

[373] Boncheva M. Magnetic self-assembly of three-dimensional surfaces from planar sheets. Proc Natl Acad Sci 2005;102:3924-9.

[374] In HJ, Lee H, Nichol AJ, Kim SG, Barbastathis G. Carbon nanotube-based magnetic actuation of origami membranes. J Vac Sci Technol B Microelectron Nanometer Struct 2008;26:2509-12.

[375] Iwase E, Shimoyama I. Multistep sequential batch assembly of three-dimensional ferromagnetic microstructures with elastic hinges. J Microelectromechanical Syst 2005;14:1265-71.

[376] Yi YW, Liu C. Magnetic actuation of hinged microstructures. J Microelectromechanical Syst 1999;8:10-7. 
[377] Ahmed S, Ounaies Z, Frecker M. Investigating the performance and properties of dielectric elastomer actuators as a potential means to actuate origami structures. Smart Mater Struct 2014;23:094003/1-14.

[378] Suzuki A, Tanaka T. Phase transition in polymer gels induced by visible light. Nature 1990;346:345-7.

[379] Li MH, Keller P, Li B, Wang X, Brunet M. Light-Driven Side-On Nematic Elastomer Actuators. Adv Mater 2003;15:569-72.

[380] Zeng H, Wasylczyk P, Parmeggiani C, Martella D, Burresi M, Wiersma DS. Light-Fueled Microscopic Walkers. Adv Mater 2015;27:3883-7.

[381] He H, Guan J, Lee JL. An oral delivery device based on self-folding hydrogels. J Controlled Release 2006;110:339-46.

[382] Shim TS, Kim SH, Heo CJ, Jeon HC, Yang SM. Controlled Origami Folding of Hydrogel Bilayers with Sustained Reversibility for Robust Microcarriers. Angew Chem Int Ed 2012;51:1420-3.

[383] Jamal M, Kadam SS, Xiao R, Jivan F, Onn TM, Fernandes R, Nguyen TD, Gracias DH. Bio-Origami Hydrogel Scaffolds Composed of Photocrosslinked PEG Bilayers. Adv Healthc Mater 2013;2:1142-50.

[384] Gultepe E, Randhawa JS, Kadam S, Yamanaka S, Selaru FM, Shin EJ, Kalloo AN, Gracias DH. Biopsy with Thermally-Responsive Untethered Microtools. Adv Mater 2013;25:514-9.

[385] Boire TC, Gupta MK, Zachman AL, Lee SH, Balikov DA, Kim K, Bellan LM, Sung HJ. Pendant allyl crosslinking as a tunable shape memory actuator for vascular applications. Acta Biomater 2015;24:53-63.

[386] Pister KSJ, Judy MW, Burgett SR, Fearing RS. Microfabricated hinges. Sens Actuators Phys 1992;33:249-56.

[387] Hubschman JP, Bourges JL, Choi W, Mozayan A, Tsirbas A, Kim CJ, Schwartz SD. "The Microhand": a new concept of micro-forceps for ocular robotic surgery. Eye 2010;24:364-7.

[388] Maitland DJ, Metzger MF, Schumann D, Lee A, Wilson TS. Photothermal properties of shape memory polymer micro-actuators for treating stroke. Lasers Surg Med 2002;30:1-11. 
[389] Frecker MI, Powell KM, Haluck R. Design of a Multifunctional Compliant Instrument for Minimally Invasive Surgery. J Biomech Eng 2005;127:990-3.

[390] Wehner M, Tolley MT, Mengüç Y, Park YL, Mozeika A, Ding Y, Onal C, Shepherd RF, Whitesides GM, Wood RJ. Pneumatic Energy Sources for Autonomous and Wearable Soft Robotics. Soft Robot 2014;1:263-74.

[391] Chien CW, Lee K, Shlian M, Forrest S, Shtein M, Ku PC. Flat-Plate Photovoltaics with Solar-Tracking Origami Micro-Concentrator Arrays. Optical Society of America 2015. p. JW2A.103.

[392] Zarzar LD, Kim P, Aizenberg J. Bio-inspired Design of Submerged HydrogelActuated Polymer Microstructures Operating in Response to $\mathrm{pH}$. Adv Mater 2011;23:1442-6.

[393] Chen CS, Breslauer DN, Luna JI, Grimes A, Chin W, Lee LP, Khine M. ShrinkyDink microfluidics: 3D polystyrene chips. Lab Chip 2008;8:622-4.

[394] Guo X, Li H, Yeop Ahn B, Duoss EB, Hsia KJ, Lewis JA, Nuzzo RG. Two- and three-dimensional folding of thin film single-crystalline silicon for photovoltaic power applications. Proc Natl Acad Sci 2009;106:20149-54.

[395] Sterman Y, Demaine ED, Oxman N. PCB Origami: A Material-Based Design Approach to Computer-Aided Foldable Electronic Devices. J Mech Des 2013;135:114502/1-4.

[396] Song Z, Ma T, Tang R, Cheng Q, Wang X, Krishnaraju D, Panat R, Chan CK, Yu H, Jiang H. Origami lithium-ion batteries. Nat Commun 2014;5:3140/1-6.

[397] Chen CM, Chiang CL, Lai CL, Xie T, Yang S. Buckling-Based Strong Dry Adhesives Via Interlocking. Adv Funct Mater 2013;23:3813-23.

[398] Aten QT, Jensen BD, Tamowski S, Wilson AM, Howell LL, Burnett SH. Nanoinjection: pronuclear DNA delivery using a charged lance. Transgenic Res 2012;21:1279-90.

[399] Lee MH, Huntington MD, Zhou W, Yang JC, Odom TW. Programmable Soft Lithography: Solvent-Assisted Nanoscale Embossing. Nano Lett 2011;11:311-5.

[400] Pentlicki CJ. Self-deployable solar cell panel. US patent 4133501 A 1979. 
[401] Anonymous, NASA. Elastic Memory Composite Hinges Tested on Shuttle. NASA Tech Briefs, http://www.techbriefs.com/component/content/article/1344 2007;31:1.

[402] Bowen LA, Grames CL, Magleby SP, Howell LL, Lang RJ. A Classification of Action Origami as Systems of Spherical Mechanisms. J Mech Des 2013;135:111008/1-7.

[403] Zirbel SA, Trease BP, Thomson MW, Lang RJ, Magleby SP, Howell LH. HanaFlex: a large solar array for space applications. Proc SPIE 2015;9467:94671C/1-9.

[404] Lee N, Pellegrino S. Packaging and deployment strategies for synthetic aperture radar membrane antenna arrays. IEEE (URSI GASS) 2014. p. 1-4.

[405] Pandey S, Ewing M, Kunas A, Nguyen N, Gracias DH, Menon G. Algorithmic design of self-folding polyhedra. Proc Natl Acad Sci USA 2011;108:19885-90.

[406] Pandey S, Johnson D, Kaplan R, Klobusicky J, Menon G, Gracias DH. SelfAssembly of Mesoscale Isomers: The Role of Pathways and Degrees of Freedom. PLoS ONE 2014;9:e108960/1-7.

[407] Zeng C, Seino H, Ren J, Yoshie N. Polymers with Multishape Memory Controlled by Local Glass Transition Temperature. ACS Appl Mater Interfaces 2014;6:2753-8.

[408] Raviv D, Zhao W, McKnelly C, Papadopoulou A, Kadambi A, Shi B, Hirsch S, Dikovsky D, Zyracki M, Olguin C, Raskar R, Tibbits S. Active Printed Materials for Complex Self-Evolving Deformations. Sci Rep 2014;4:7422/1-8.

[409] Ge Q, Dunn CK, Qi HJ, Dunn ML. Active origami by 4D printing. Smart Mater Struct 2014;23:094007/1-15.

[410] Williams SE, Bennett AB. Leaf Closure in the Venus Flytrap: An Acid Growth Response. Science 1982;218:1120-2.

[411] Forterre Y, Skotheim JM, Dumais J, Mahadevan L. How the Venus flytrap snaps. Nature 2005;433:421-5. 


\section{Figure Captions}

Figure 1. Cross-sectional illustrations of strategies to generate 3D shapes by using shape-programming of polymeric materials in four categories: 1) conventional fabrication; 2) induced surface topography on a macroscopically flat substrate; 3) 3D structures by bending; and 4) 3D structures by folding. The dashed black line marks the original 2D substrate prior to shape change.

Figure 2. Illustration of the difference between folding and bending of sheets (in a cross-sectional view): a) ideal case of folding with localized deformation; b) in practice, folding is defined when the deformed region (red) is small relative to the sample size (blue); c) in practice, bending is defined when the deformation region is commiserate with the sample size; d) ideal case of bending with global deformation; e) a series of local folds can lead to a global bend. Red colors denote the regions of deformation.

Figure 3. Schematic of conventional lithographic methods that expose polymeric films to patterns of photons, electrons, or ions. Only negative photoresists are shown here for the sake of illustration.

Figure 4. a) Schematic of the formation of wrinkles on an elastic substrate by pre-stretching; b) Wavelengths of multiple generatio.ns of wrinkles can form on PDMS sheets by using large pre-strains. [81], Copyright 2050. Adapted with permission from Nature.; c) optical microscopy images (top view) of wrinkles with different orientation preference due to the applied strain in different directions. [76], Copyright 2010. Reproduced with permission from John Wiley \& Sons Inc.

Figure 5. a) Schematics and optical microscopy images from b) top view and c) side view for typical wrinkles (left column), creasing (middle column) and delamination (right column). [118], Copyright 2013. Reproduced with permission from the ASME.

Figure 6. a) Schematic of the time evolution for spinodal dewetting (left) and corresponding experimental result (right). [122], Copyright 2012. Adapted with permission from the Royal Society of Chemistry.; b) Optical microscope image of dewetting of poly(methyl methacrylate) (PMMA) on a patterned PDMS substrate. [130], Copyright 2007. Reproduced with permission from Elsevier Ltd.; c) Schematic of 3D structures induced by an electric field at polymer/air bilayer. [132], Copyright 2000. Reproduced with permission from Nature; d) Schematic of 3D structures induced by electric field at polymer/polymer/air trilayer. [136], Copyright 2006. Reproduced with permission from the American Chemical Society.; e) SEM images of cage-type [136], Copyright 2006. Reproduced with permission from the American Chemical Society. ; f) column structure made of PMMA while removing polystyrene with electric field on PMMA/PS/air trilayers with different electrode set-up. [137], Copyright 2002. Reproduced with permission from Nature.

Figure 7. AFM image of surface topography on a polymer film containing photosensitive azo groups after exposing to patterned UV light to generate a surface-plasmon field. [138], Copyright 2011. Reproduced with permission from the Royal Society of Chemistry. 
Figure 8. Illustration of sample preparation procedures on shape memory polymer to form surface topography (e.g., wrinkling). [142], Copyright 2011. Reproduced with permission from IOP Publishing.

Figure 9. Surface topography due to shape memory effect in an acrylate-based SMP (cured from methyl methacrylate (MMA), poly(ethylene glycol dimethacrylate) (PEGDMA) as crosslinker and 2,2-dimethoxy-2-phenylacetodphenone (initiator)). Schematics (top) and images (bottom) for different stages: a) permanent pattern molded by thermally embossing nanoimprint lithography at $\sim 180^{\circ} \mathrm{C}$; b) $2 \mathrm{D}$ planar surface after programing with a flat mold; and c) recovered surface topography after heating at $\sim 120^{\circ} \mathrm{C}$. The pattern has a pitch of $\sim 800 \mathrm{~nm}$ and a height of $\sim 180 \mathrm{~nm}$. [140], Copyright 2011. Adapted with permission from John Wiley \& Sons Inc.

Figure 10. Examples of $3 \mathrm{D}$ structures induced by controlling the stress within sheets of polymer gels: a) bending is triggered by a temperature change to a thermal responsive PNIPAAm bilayer laminate. [160], Copyright 2011. Adapted with permission from the Royal Society of Chemistry.; b) bilayer structure with one passive layer (colors other than green, top layer) and one temperature-sensitive hydrogel (green layer) to induce the bending. [165], Copyright 2013. Adapted with permission from IOP Publishing.; c) 3D curved shapes are generated when asymmetrical swelling occurs due to highly crosslinked dots within a low crosslinked matrix. [170], Copyright 2012. Reproduced with permission from the American Association for the Advancement of Science.; d) complex helical structure can be formed when a planar sheet patterned with chemically distinct regions of hydrogel swells. [176], Copyright 2013. Adapted with permission from Nature.

Figure 11. a) Schematic to illustrate the light-induced crosslinking gradient across the film thickness of SU-8 film, and resulting bending of the film in different solvents; b) Fluorescence images of actuation of flower-shaped structures. Scale bars are $100 \mu \mathrm{m}$. [178], Copyright 2011. Reproduced with permission from Nature.

Figure 12. a) $3 \mathrm{~A}$ hydrogel bends into a $3 \mathrm{D}$ coil by using multiple folds patterned via ionoprinting lines of copper ions in a hydrogel via the use of a copper electrode; b) ionprint lines are stiffer than the rest of the gel, which causes gels to swell asymmetrically. A consequent gel gripper is demonstrated to catch and release a small blue cube of PDMS $(\sim 1 \mathrm{~g})$ in ethanol and water, respectively. The scale bar is 10 mm. [187], Copyright 2013. Adapted with permission from Nature.

Figure 13. a) Schematics of asymmetrical inflation of a $2 \mathrm{D}$ sheet by applying different thickness of elastomers (top row) or using composite materials with different Young's Modulus ( $\left.\mathrm{E}_{\mathrm{a}}, \mathrm{E}_{\mathrm{b}}\right)$. [24], Copyright 2011. Adapted with permission from John Wiley \& Sons Inc.; b) Example of a paper-Ecoflex composite showing asymmetrical actuation. [197], Copyright 2012. Adapted with permission from John Wiley \& Sons Inc.; c) Micro hand robotic system driven by pneumatic balloon actuator. [199], Copyright 2007. Reproduced with 
permission from the IEEE.; d) Demonstration of gripping an uncooked egg. [24], Copyright 2011. Reproduced with permission from John Wiley \& Sons Inc.

Figure 14. a) 3D shape change of a liquid crystal elastomer film upon heating. [209], Copyright 2015. Reproduced with permission from American Association for the Advancement of Science.; b) Bending of a cantilever made of azo-liquid crystal network under the exposure of $442 \mathrm{~nm}$ light with different polarization angles. [218], Copyright 2011. Reproduced with permission from the Royal Society of Chemistry.

Figure 15. Illustration of representative photoisomerizable molecules: a) trans-cis photoisomerization of azobenzenes; b) ionic dissociation of triphenylmethane leuco derivatives; c) cinnamic acid group; and d) photos demonstrating bending of polymer sheet by applying polarized light with different angles. [220], Copyright 2006. Reproduced with permission from John Wiley \& Sons Inc.

Figure 16. a) A typical piezoelectric sheets sandwiched by electrodes. The dashed lines indicated the deformed shape in response to an electric field. [244], Copyright 1991. Reproduced with permission from Elsevier Ltd.; b) Schematic of piezoelectric PVDF films used as a pressure sensor due to the charge arises from deflection of the film. [238], Copyright 2008. Reproduced with permission from Elsevier Ltd.

Figure 17. Schematics of the comparison between (a) conventional self-assembly and (b) folding. [57], Copyright 2010. Adapted with permission from John Wiley \& Sons Inc.

Figure 18. a) Schematic of shrinking polyimide fabricated as a hinge. [268], Copyright 2006. Reproduced with permission from Springer .; b) 3D structure (right) generated from the template (left) of patterned copper/Kapton sheet with pre-strained polymer strips as hinges that respond to temperature. [269], Copyright 2011. Reproduced with permission from the International Society for Optics and Photonics.; c) Microgripper triggered by temperature or chemicals in the biological environment with a patterned responsive polymer (red, top layer). [38], Copyright 2009. Reproduced with permission from the National Academy of Sciences of the USA.

Figure 19. a) Folding of a sandwiched sheet with shrink film in the middle while heat resistant materials on the top and bottom layers. The arrows show the shrinking directions. [274], Copyright 2014. Reproduced with permission from the IEEE.; b) a fluorescence image of a folded flapping bird (bottom) made from the trilayer film (top) with photo-crosslinkable temperature-responsive polymer (PNIPAM) in between. [279], Copyright 2015. Reproduced with permission from John Wiley \& Sons Inc.; c) An icosahedron (bottom) made from the template (top) incorporated with pre-strained polymers inside a trilayer laminate. The folding is actuated with uniform heating in an oven. [273], Copyright 2014. Adapted with permission from IOP Publishing. 
Figure 20. Photographs of folded cubes from a pre-programmed 2D shape-memory polymer sheet that folds in response to heat. [282], Copyright 2010. Reproduced with permission from John Wiley \& Sons Inc.

Figure 21. a) SMA actuators can be folded by applying Joule-heating (red arrows show the heating location). b) Demonstration of folding a "boat" from a 2D planar composite sheets patterned with SMA hinges which can cause the folding through Joule-heating. [20], Copyright 2010. Reproduced with permission from the National Academy of Sciences of the USA.

Figure 22. a) Schematic of a typical thermo-mechanical process for programming shape-memory polymers. $\mathrm{T}<\mathrm{T}_{\text {trans }}$ is represented in blue color while $\mathrm{T}>\mathrm{T}_{\text {trans }}$ is in red color; and b) A representative cyclic strain-temperature-stress diagram. In this specific case, a heated sample starts from the "asterisk" (i.e., low stress, high temperature) and is (i) deformed (elongated by stretching), (ii) cooled and then (iii) the stress applied for deformation is released. (iv) The original shape of the sample is recovered by heating again. [130], Copyright 2007. Reproduced with permission from the Royal Society of Chemistry.

Figure 23. Summary of molecular structures and switching mechanisms of SMPs. [310], Copyright 2013. Adapted with permission from the Royal Society of Chemistry.

Figure 24. a) Schematic of patterned hinge through a photomask due to photo-induced stress relaxation in a polymer (left) and a closed box with multiple hinges created (right). [5], Copyright 2012. Reproduced with permission from the American Institute of Physics.; b) Schematic of local crosslink gradient through poly (N-isopropylacrylamide-co-acrylic acid) (pNIPAM-AAc) and induced folding, and the demonstrated folding and unfolding of the gripper. [272], Copyright 2014. Reproduced with permission from IOP Publishing.

Figure 25. Photographs of 3D structures formed by folding of pre-strained polymer sheets patterned with black "hinges" using a desktop printer. The black ink absorbs light from a lamp to induce folding via localized heating. a) Single line with hinge width (w) of 1 mm; b) three lines patterned on alternating sides with hinge with of $1 \mathrm{~mm}$ and $12 \mathrm{~mm}$ spacing; c) rectangular box $(20 \mathrm{~mm} \times 10 \mathrm{~mm} \times 10 \mathrm{~mm}$, w = $1.5 \mathrm{~mm})$; d) tetrahedral box with a square bottom facet (10 mm x $10 \mathrm{~mm}$ ) and hinge widths of $2.0 \mathrm{~mm})$. [324], Copyright 2012. Reproduced with permission from the Royal Society of Chemistry.

Figure 26. Summary of existing active materials applied for reconfigurable or morphing structures show a trade-off between maximum strain and modulus. Red dash curve on the top right part shows the limit of existing materials for these two materials properties. Abbreviations of the various compounds (added by the authors of this review, not the authors of the original article): CFRP: carbonfiber-reinforced polymer; FSMA: ferromagnetic shape memory alloys; G-10: fiberglass epoxy laminates ; IPMC: ionic polymer metal composite; LCE: liquid crystal elastomers; PAN:polyacrylonitrile; PMMA: poly(methyl methacrylate); PVDF: poly(vinylidene 
fluoride); PZN-PT: $(1-x) \mathrm{Pb}\left(\mathrm{Zn}_{1 / 3} \mathrm{Nb}_{2 / 3}\right) x \mathrm{PbTiO}_{3}$; PZT: lead zirconate titanate $\left(\mathrm{PbZr}_{0.52} \mathrm{Ti}_{0.48} \mathrm{O}_{3}\right)$; SMA: shape memory alloys. [327], Copyright 2010. Reproduced with permission from SAGE Publications.

Figure 27. Additional examples of applications for out-of-plane shape programming. a) A self-assembled robot by folding. [277], Copyright 2014. Reproduced with permission from the American Association for the Advancement of Science .; b) 3D dual-channel microfluidics. Scale bar is $500 \mu \mathrm{m}$. [178], Copyright 2011. Reproduced with permission from Nature.; c) Partially opened deployable array for solar panel. [403], Copyright 2015. Reproduced with permission from SPIE Proceedings. 


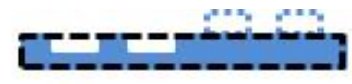

1. Conventional fabrication

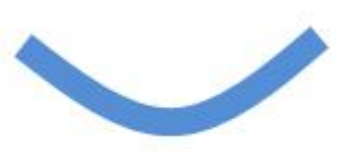

3. Bending $\swarrow$
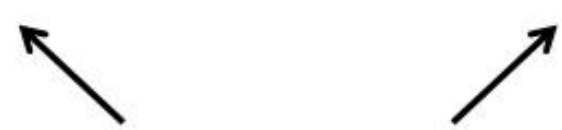

2D Plane

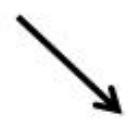

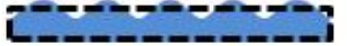

2. Induced surface topography

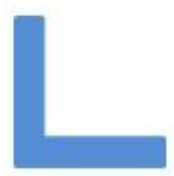

4. Folding

Figure 1. 


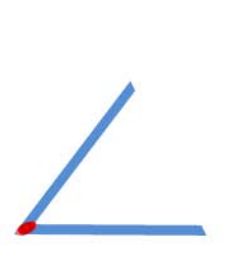

a)

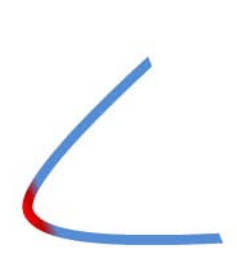

b)

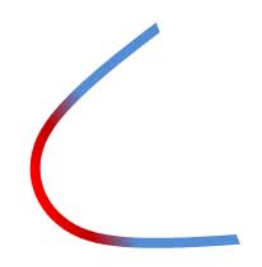

c)

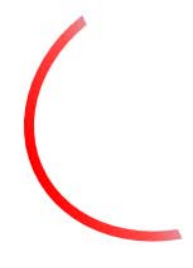

d)

Folding

Bending

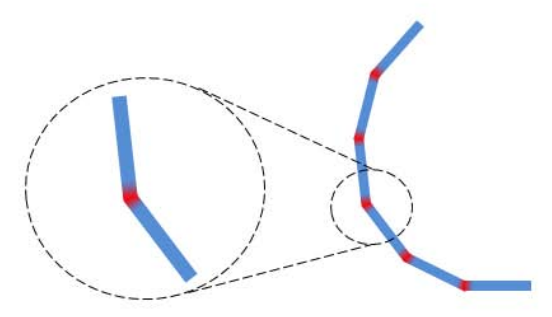

e)

Figure 2. 


\section{Substrate}

Film deposition

Photoresist
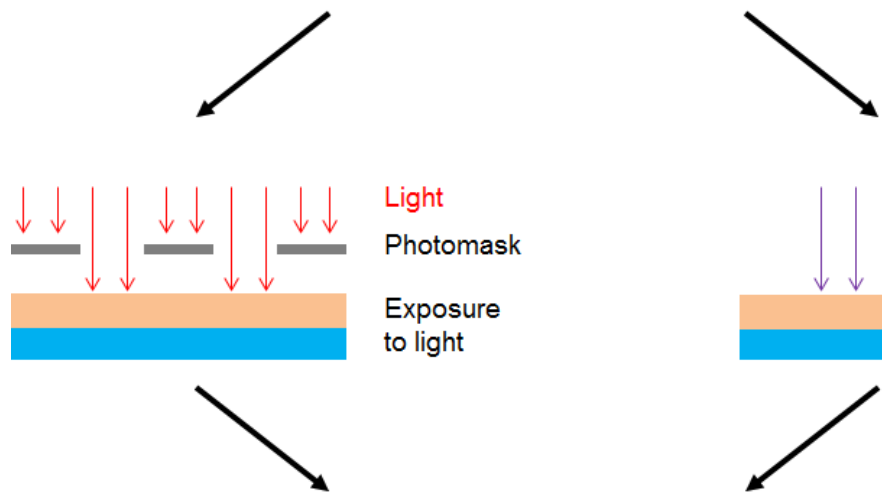

Light

Photomask

Exposure

to light

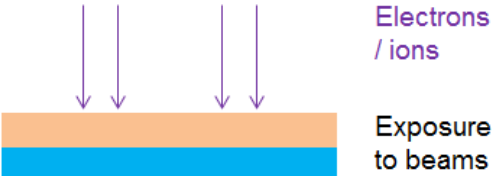

to beams
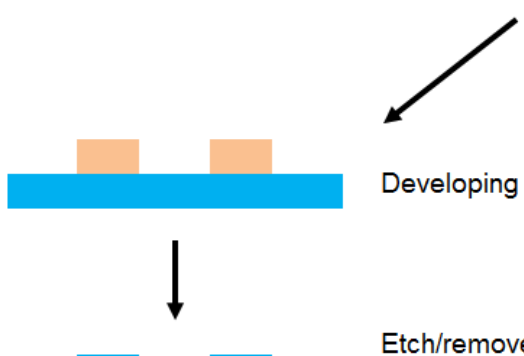

Developing

Etch/remove

photoresist

Figure 3. 
a)

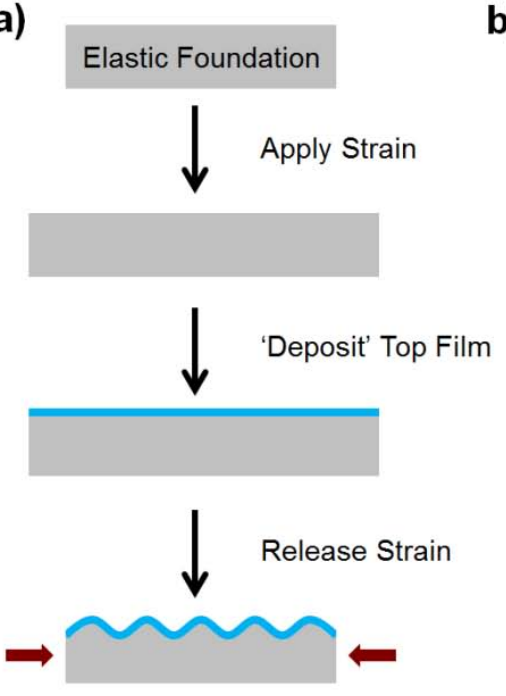

b)

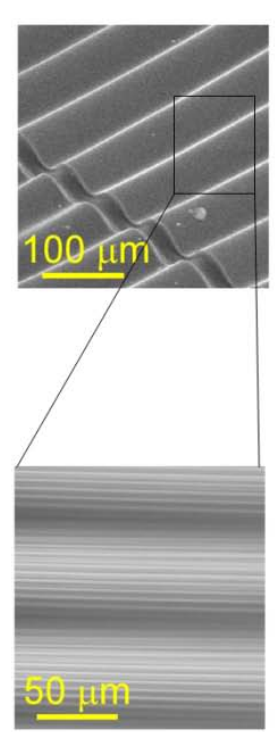

c)
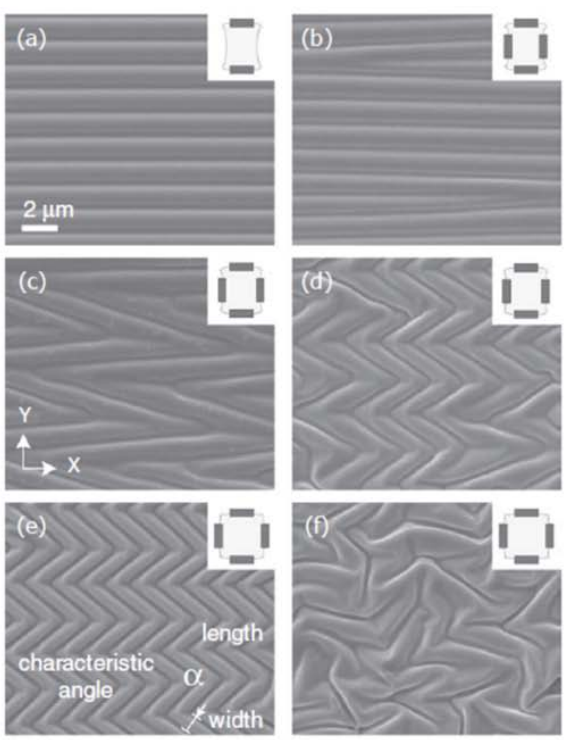

Figure $\square$. 
a)
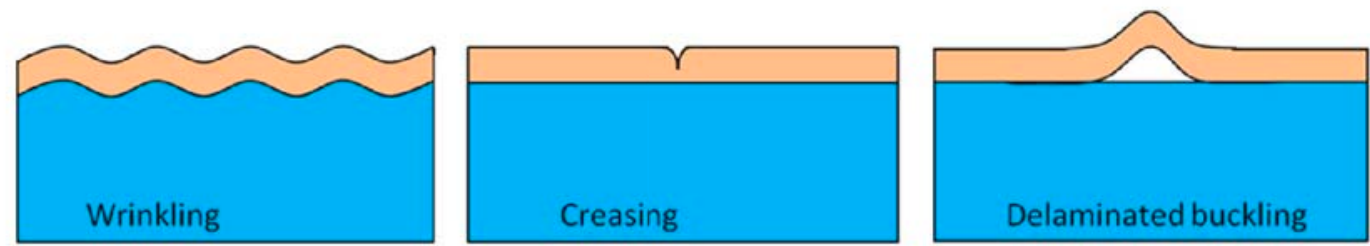

b)
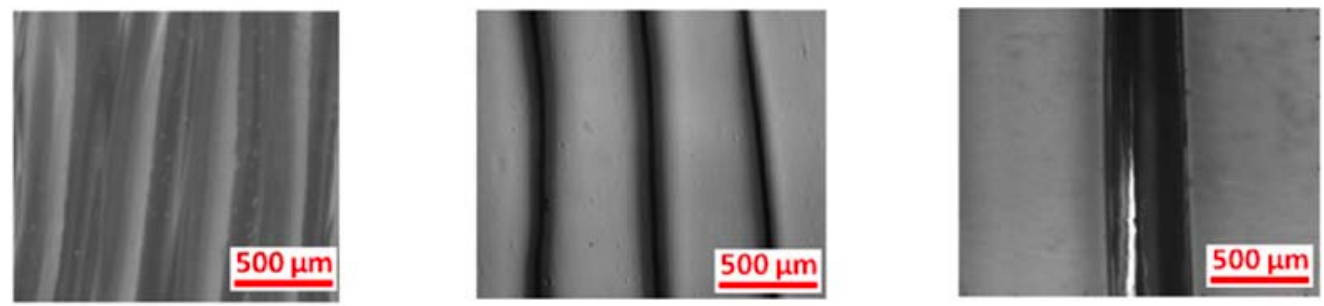

c)
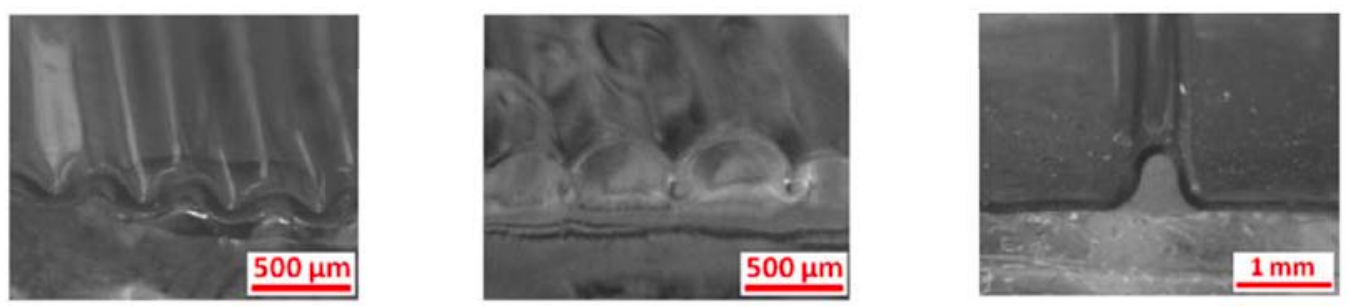

Figure 5. 
a)



c)

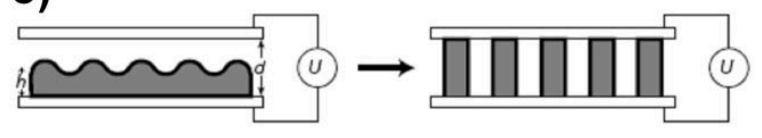

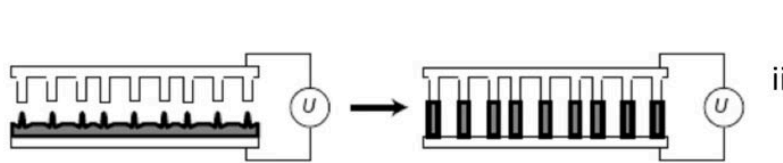

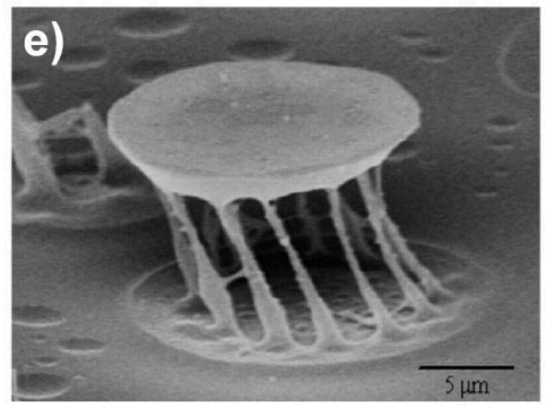

b)

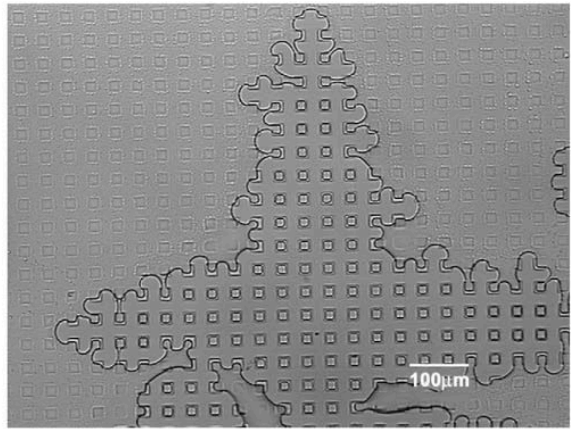

d)

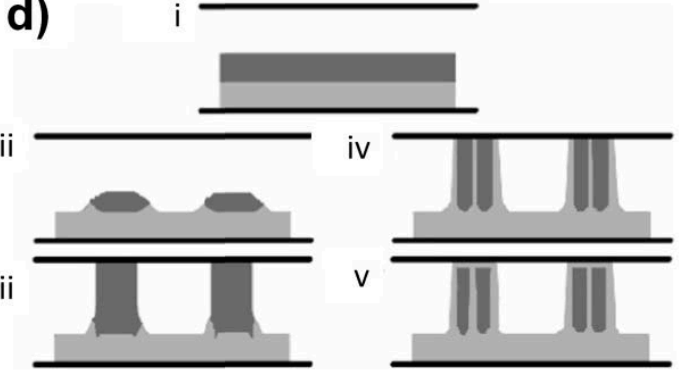

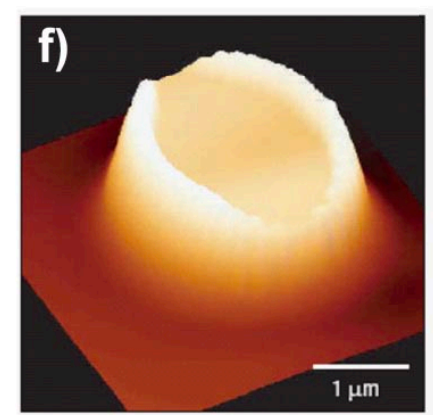

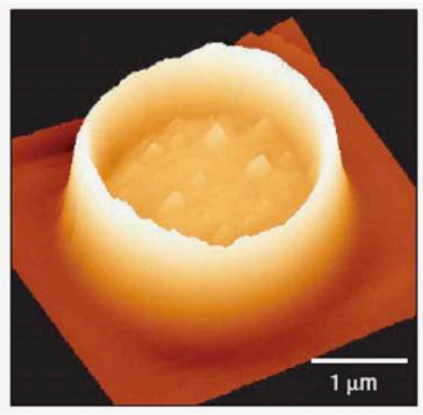

Figure 6. 

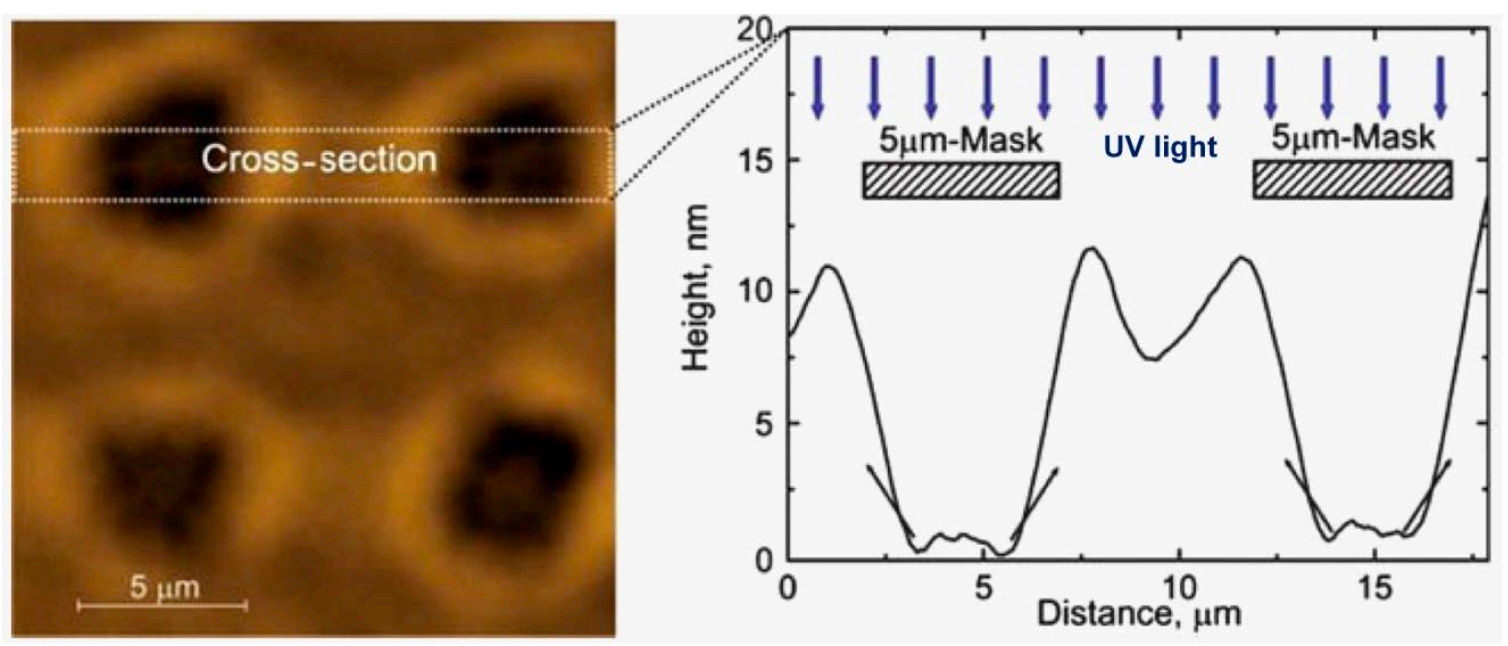

Figure 7. 


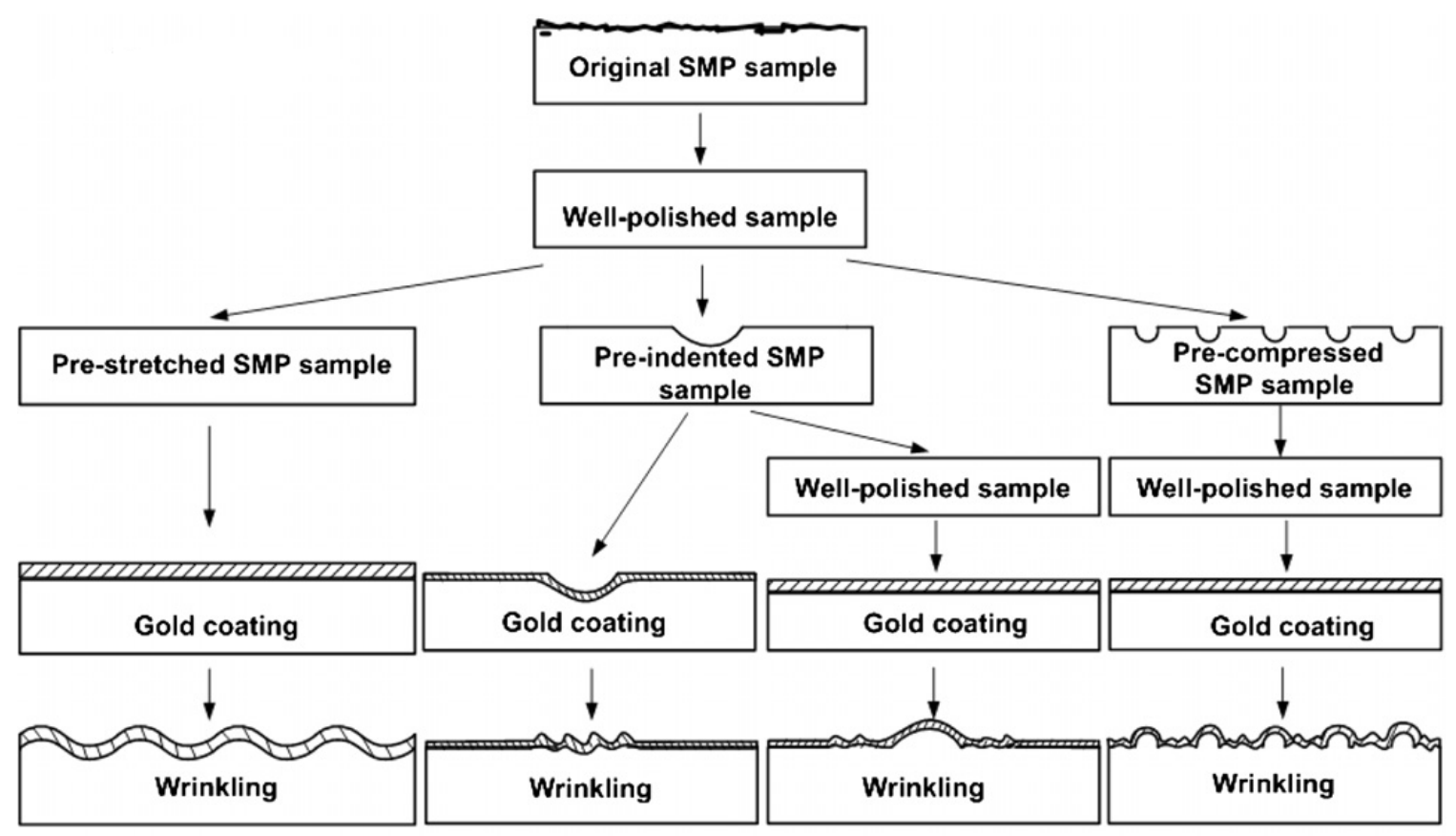

\section{Figure 8.}



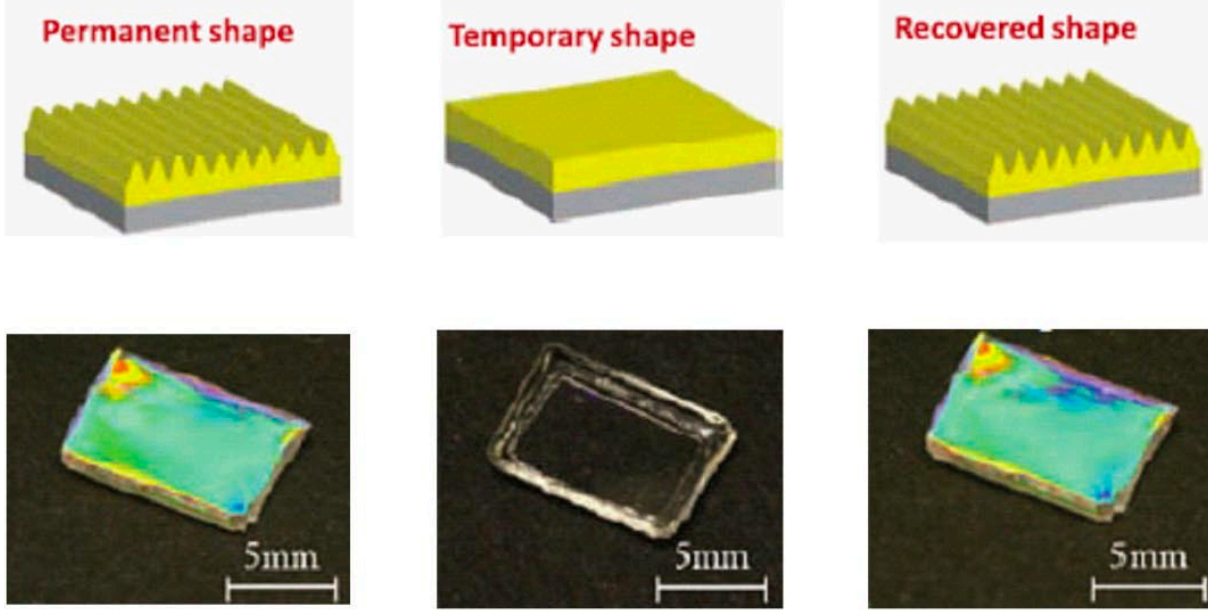

a)

b)



c)

Figure 9. 
a)

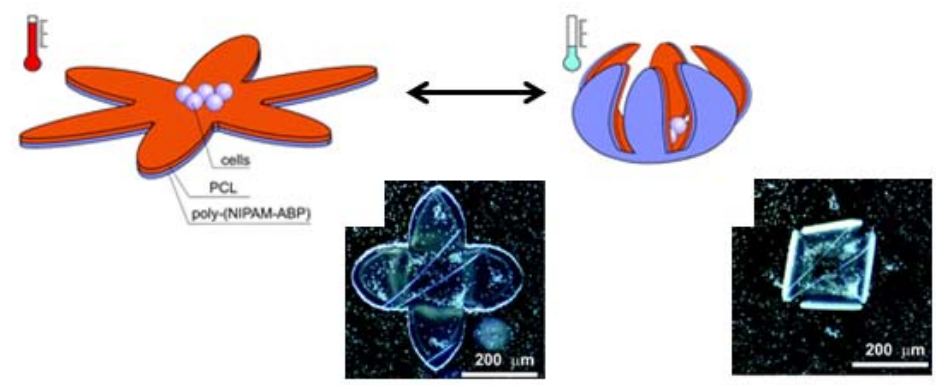

b)

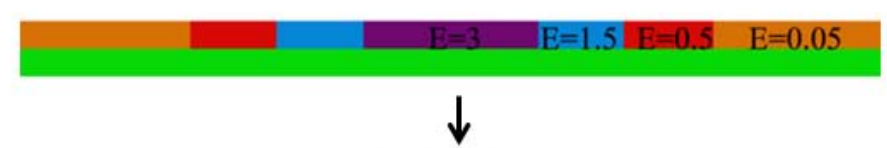

c)
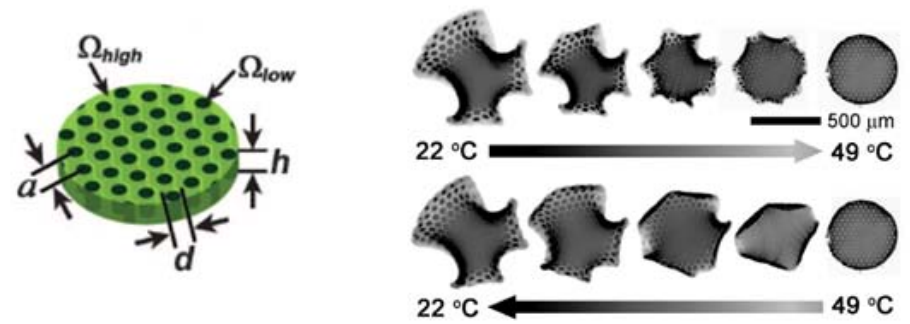

d)

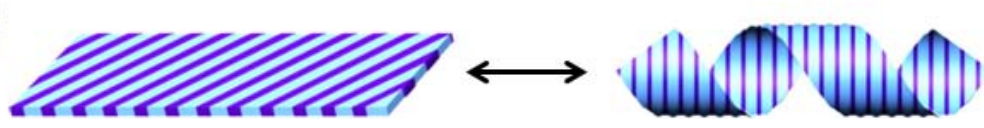

Figure 10. 

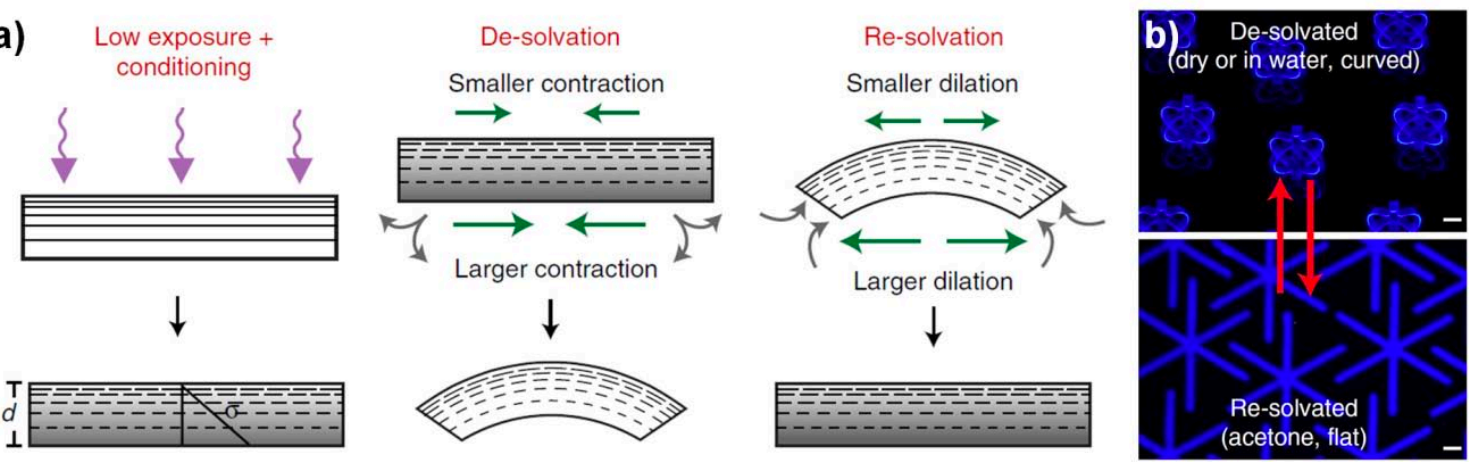

Figure 11. 

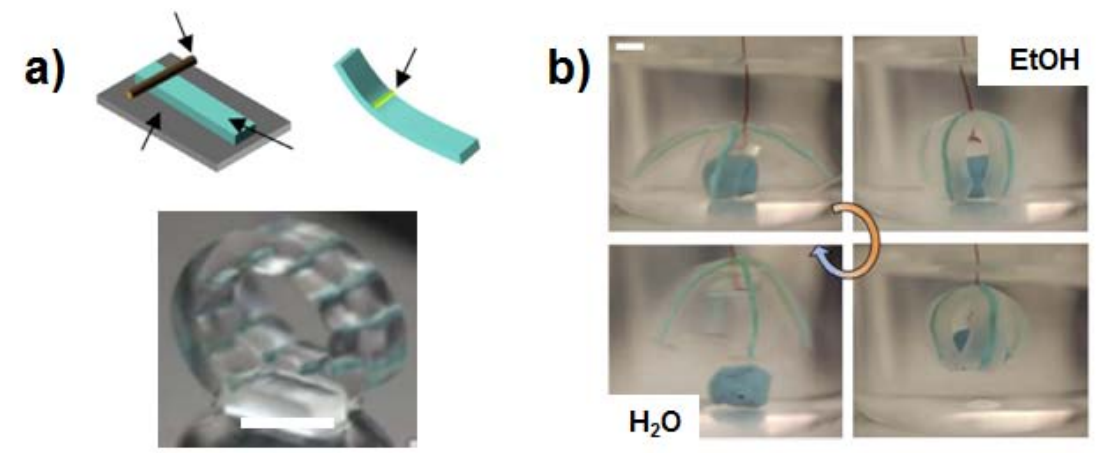

Figure 12. 

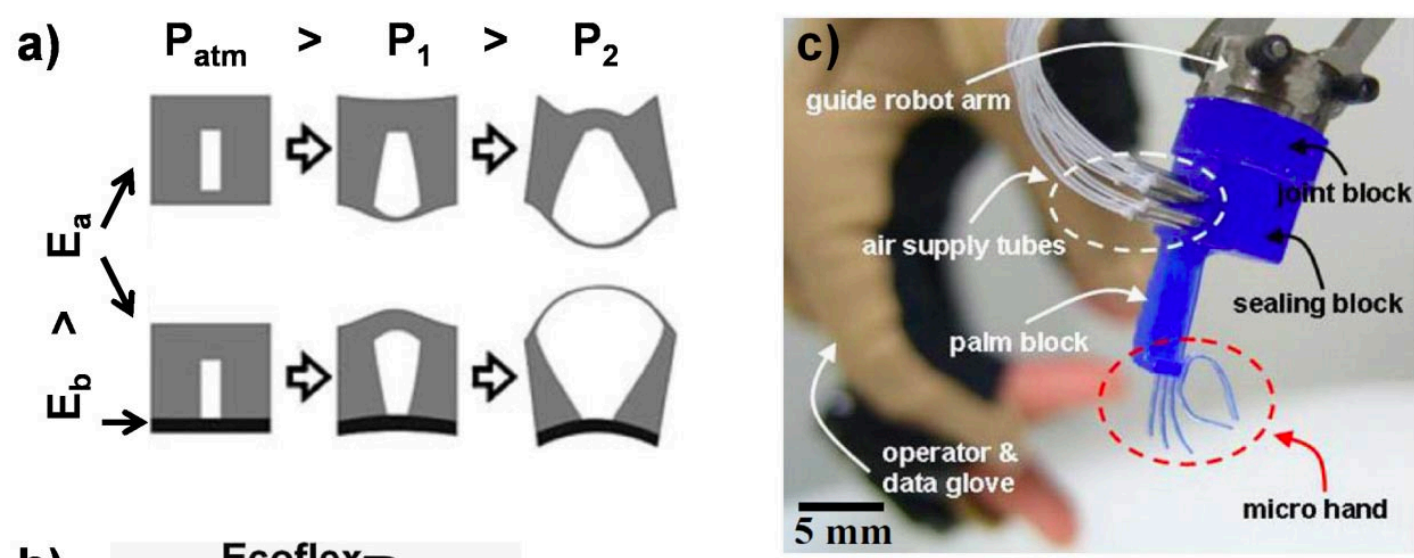

b)
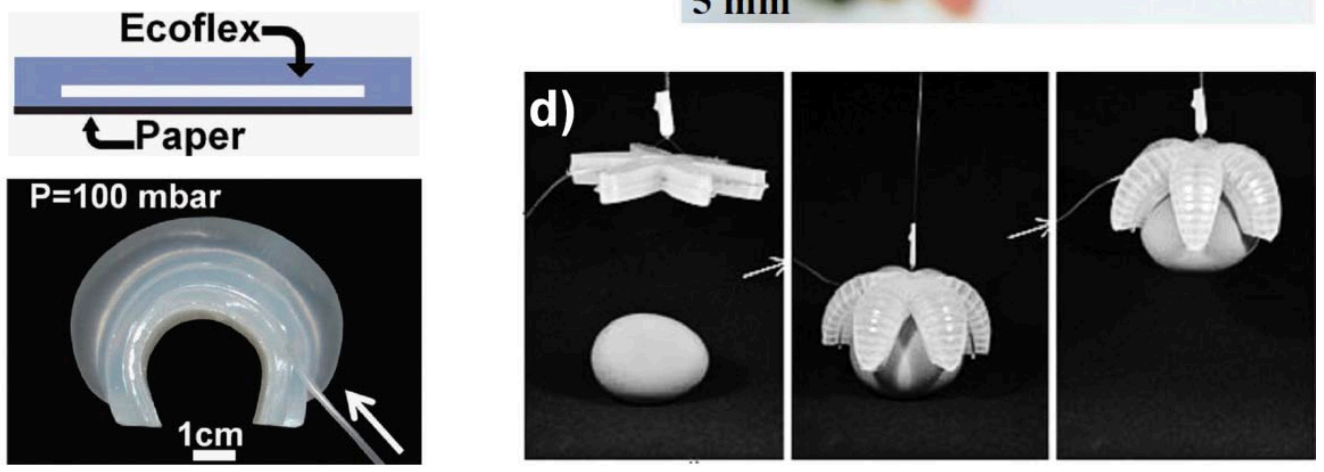

Figure 13. 
a)

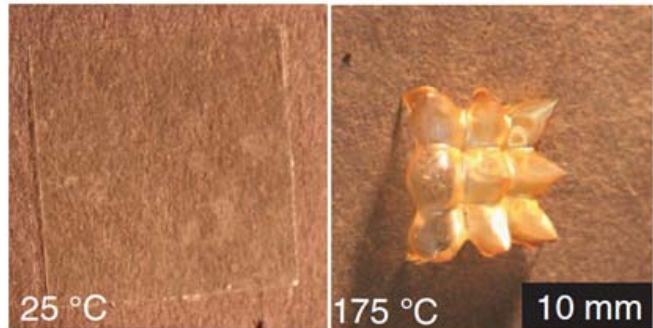

b)

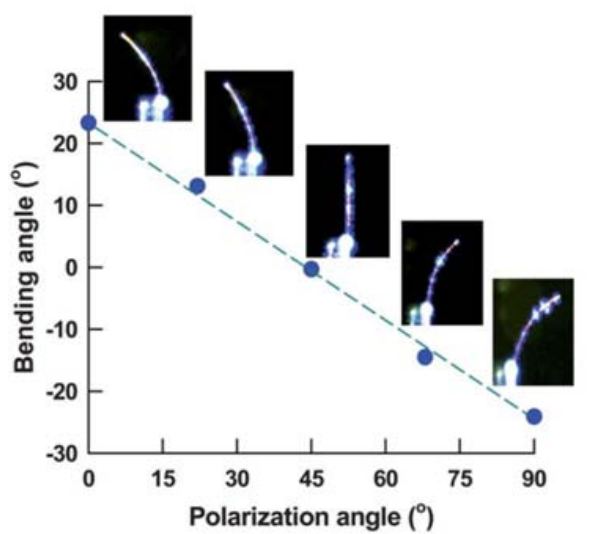

Figure 14. 
a)

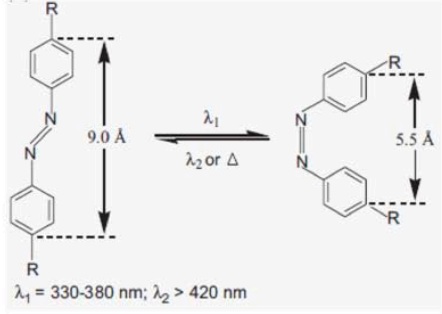

b)

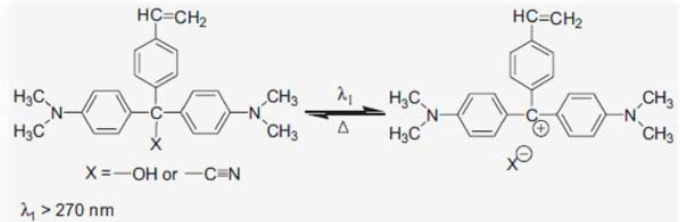

c)

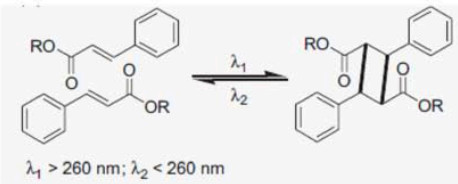

d)

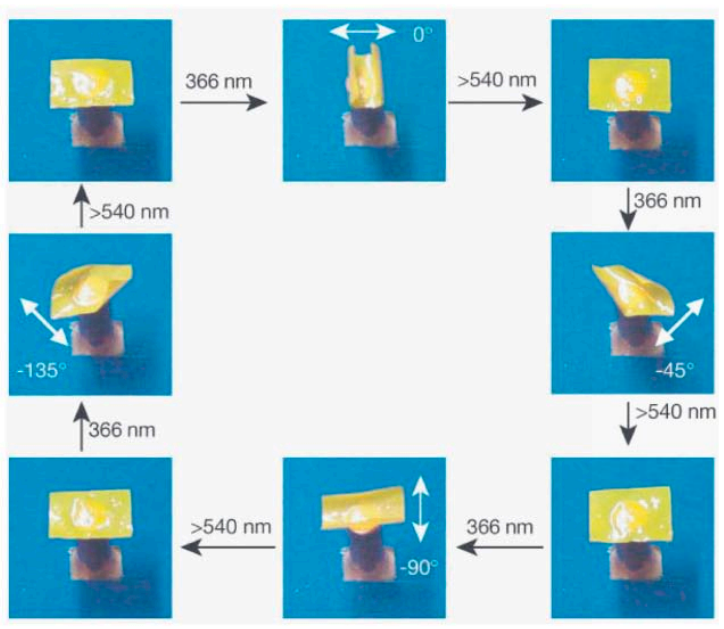

Figure 15. 
a)

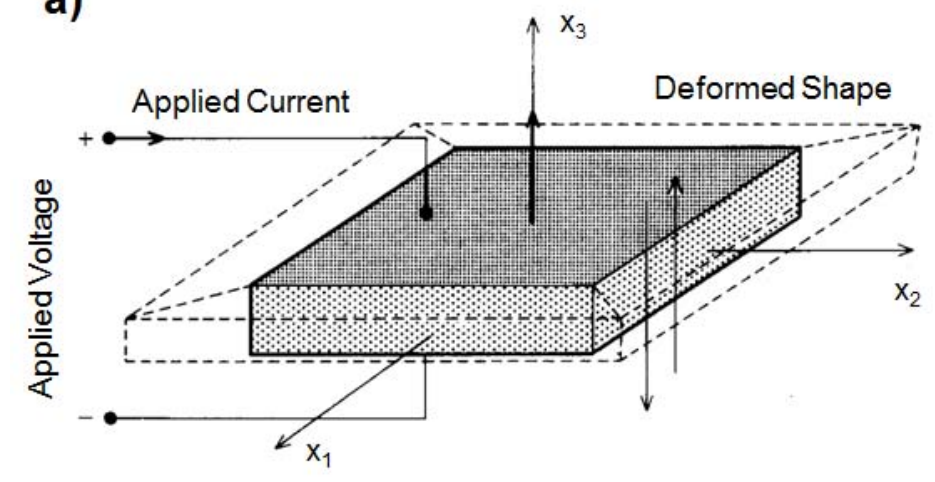

b)

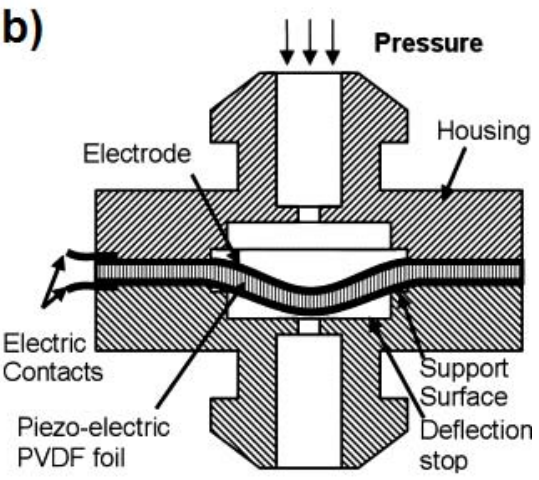

Figure 16. 

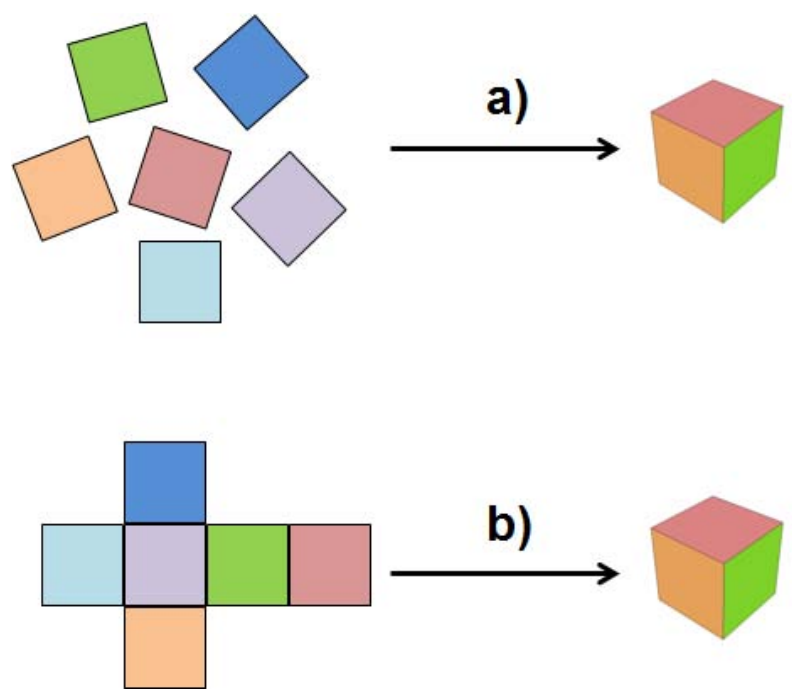

Figure 17. 
a)
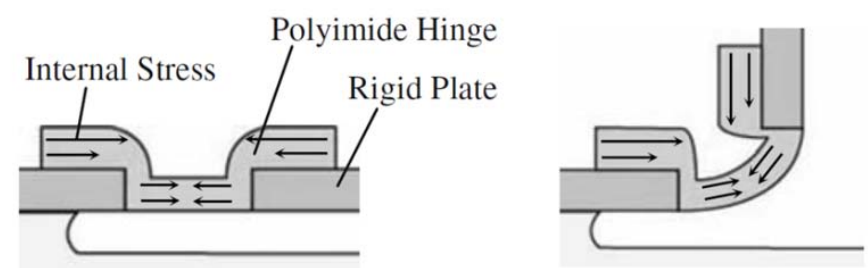

b)
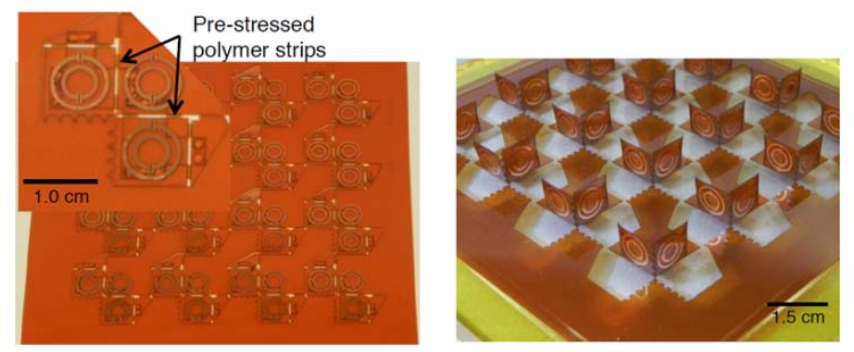

c)
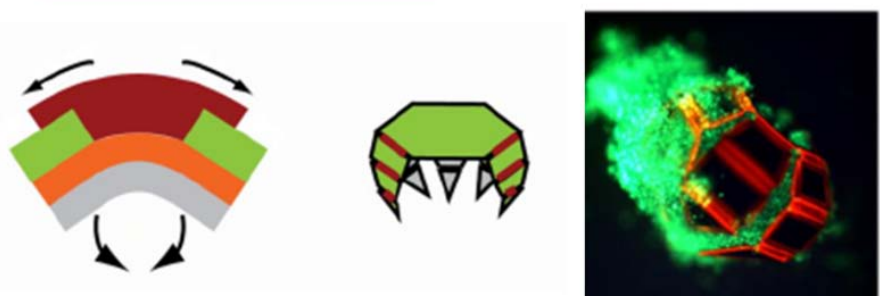

Figure 18. 
a)
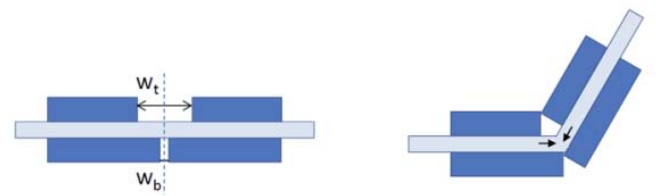

b)

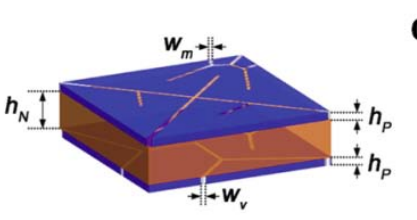

c)
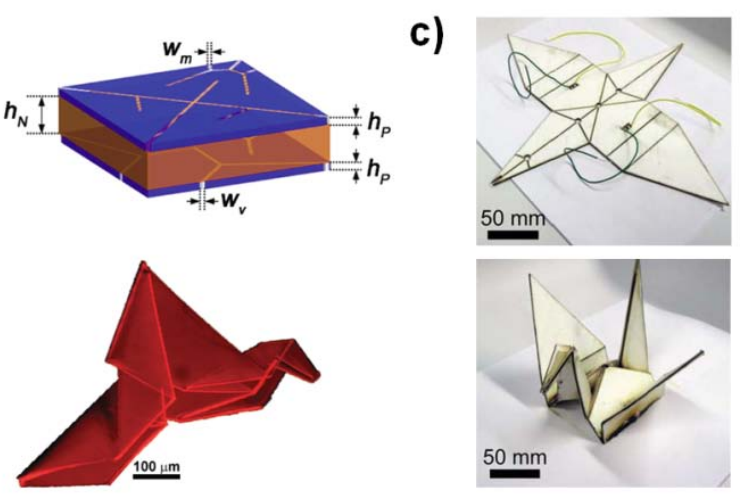

Figure 19. 


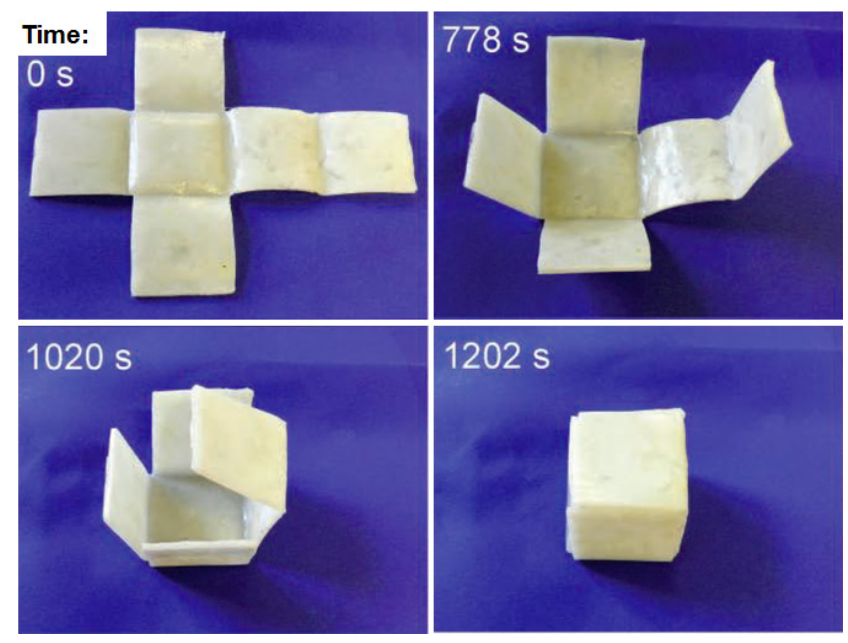

Figure 20. 
a)

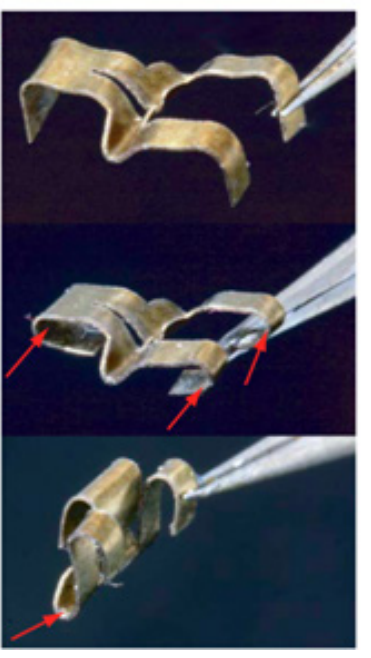

b)

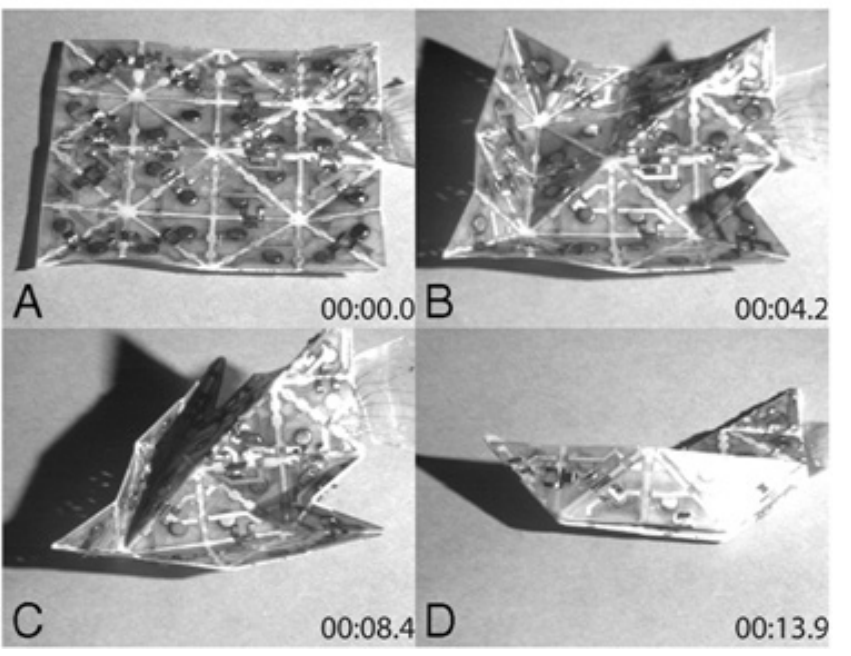

Figure 21. 
a)
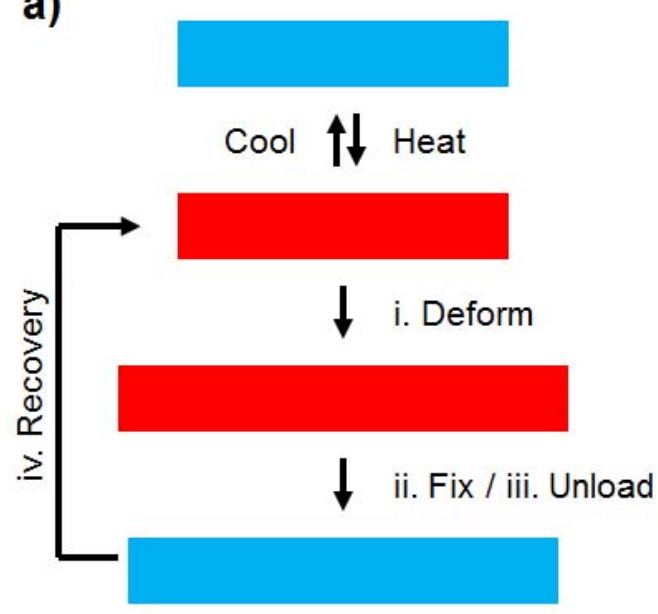

b)

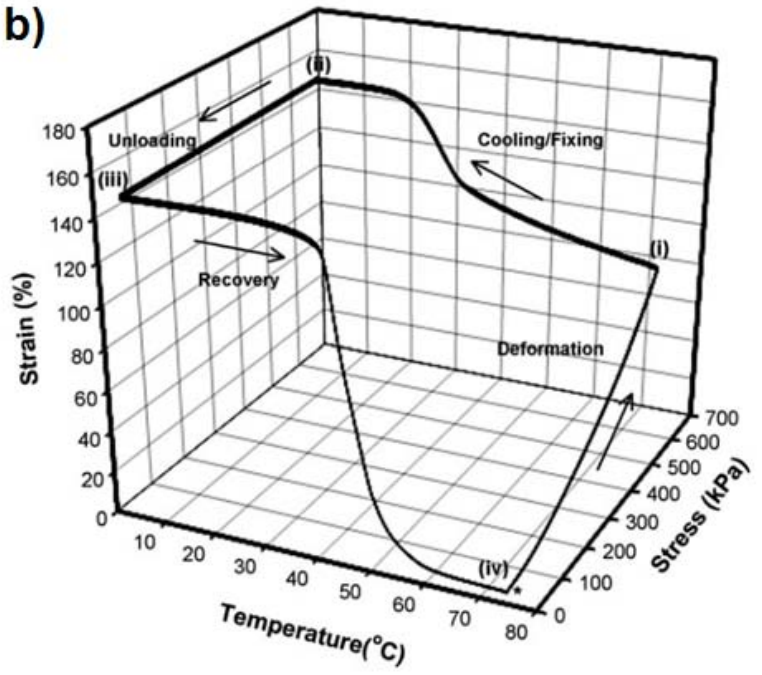

Figure 22. 




Figure 23. 
a)
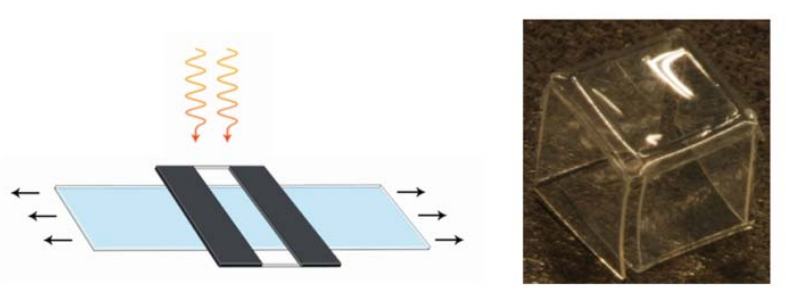

b)

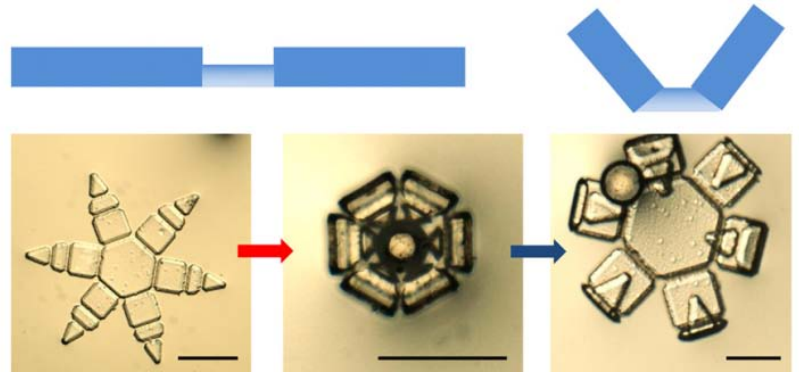

Figure 24. 


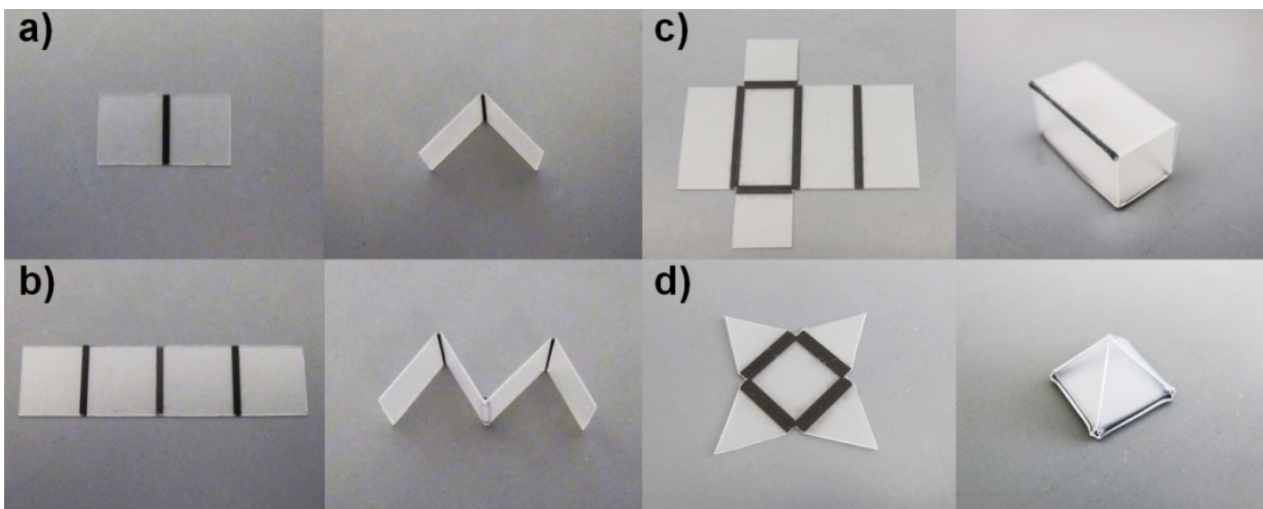

Figure 25. 




Figure 26. 

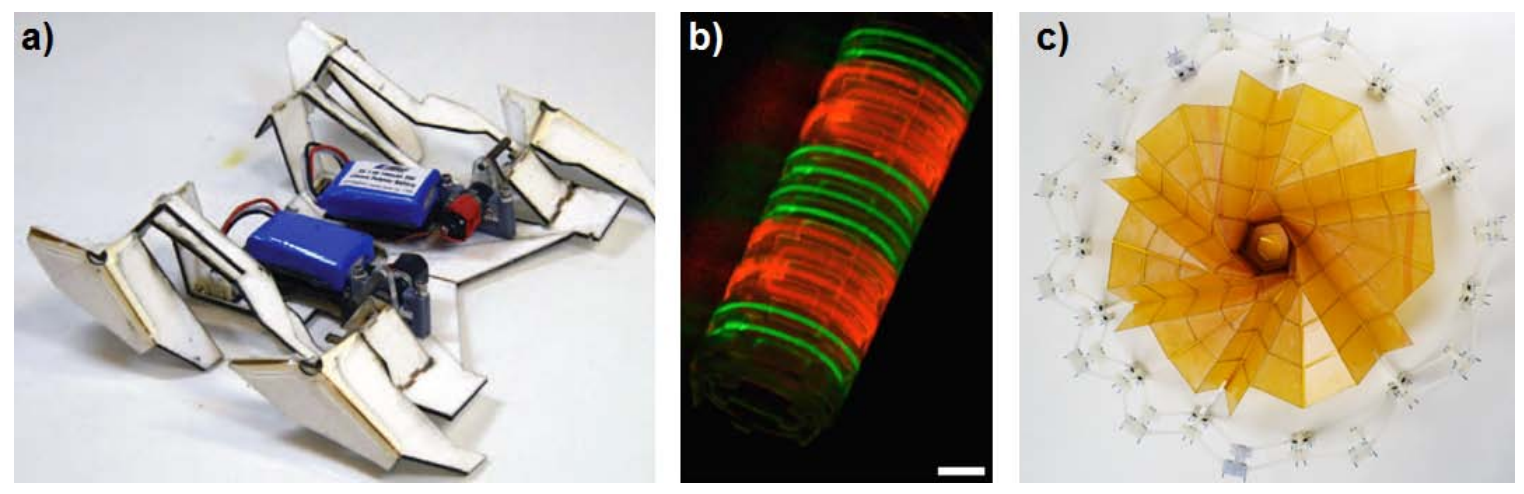

Figure 27. 
Table I. Representative approaches for folding and bending of polymer sheets. The table is organized by the phenomena and stimuli. The term "scale" here refers to the length scale of the hinges or curvature of bending.

\begin{tabular}{|c|c|c|c|c|c|c|c|}
\hline Phenomenon & Stimulus & Materials & $\begin{array}{l}\text { Length } \\
\text { scale }\end{array}$ & Advantages & Disadvantages & Reversibility & Reference \\
\hline $\begin{array}{c}\text { Differential } \\
\text { thermal } \\
\text { expansion }(e . g ., \\
\text { bimorph })\end{array}$ & Heat & $\begin{array}{c}\text { Bilayers with } \\
\text { different thermal } \\
\text { expansion } \\
\text { coefficients (e.g., } \\
\text { polymer/metal) }\end{array}$ & $\mu \mathrm{m}-\mathrm{mm}$ & $\begin{array}{l}\text { Simple and available } \\
\text { thermal actuation }\end{array}$ & $\begin{array}{l}\text { Elevated temperature } \\
\text { required, curvature } \\
\text { depends on degree of } \\
\text { mismatch; limited } \\
\text { curvature induced }\end{array}$ & Yes & $\begin{array}{c}160,164,363- \\
365]\end{array}$ \\
\hline \multirow{5}{*}{$\begin{array}{l}\text { Volumetric } \\
\text { expansion/ } \\
\text { contraction }\end{array}$} & Solvents & Gels & $\mu \mathrm{m}-\mathrm{mm}$ & $\begin{array}{c}\text { Simple triggering in } \\
\text { liquid }\end{array}$ & $\begin{array}{c}\text { Restricted to liquid } \\
\text { environment }\end{array}$ & Yes & {$[161,166,366]$} \\
\hline & Temperature & $\begin{array}{l}\text { Thermal- } \\
\text { responsive } \\
\text { polymers }(e . g ., \\
\text { temperature- } \\
\text { responsive } \\
\text { hydrogels) }\end{array}$ & $\mu \mathrm{m}-\mathrm{mm}$ & $\begin{array}{l}\text { Simple thermal } \\
\text { actuation }\end{array}$ & Asymmetry needed. & Yes & $\begin{array}{c}{[160,170,176,} \\
367,368]\end{array}$ \\
\hline & $\begin{array}{c}\text { Pressure } \\
\text { (pneumatics) }\end{array}$ & $\begin{array}{l}\text { Elastomers (e.g., } \\
\text { Ecoflex, PDMS); } \\
\text { Parylene }\end{array}$ & $\mathrm{mm}-\mathrm{cm}$ & $\begin{array}{l}\text { Inexpensive, light } \\
\text { weight, high loads; fast } \\
\text { response time } \\
(\mathrm{ms} \sim \mathrm{s} \text { depending on air } \\
\text { flow rate) }\end{array}$ & $\begin{array}{l}\text { Source/control of fluid } \\
\text { pressure needed; } \\
\text { requires mismatch in } \\
\text { flexibility/modulus } \\
\text { between layers for } \\
\text { asymmetrical bending }\end{array}$ & Yes & [197-199,369] \\
\hline & $\begin{array}{c}\mathrm{pH}, \text { ionic } \\
\text { concentration }\end{array}$ & Gels & $\mu \mathrm{m}-\mathrm{mm}$ & Simple operation & $\begin{array}{c}\text { Restriced to liquid } \\
\text { environment }\end{array}$ & Yes & $\begin{array}{c}144,148,152, \\
370]\end{array}$ \\
\hline & $\begin{array}{c}\text { Electric } \\
\text { field/chemical } \\
\text { potential }\end{array}$ & $\begin{array}{c}\text { Piezoelectric } \\
\text { polymers (e.g., } \\
\text { PVDF); } \\
\text { electroactive } \\
\text { hydrogels; ionic } \\
\text { polymers }\end{array}$ & $\mu \mathrm{m}-\mathrm{mm}$ & $\begin{array}{l}\text { Simple application of } \\
\text { electric field or } \\
\text { chemical potential }\end{array}$ & $\begin{array}{c}\text { Requires liquid } \\
\text { environment, usually } \\
\text { slow response except } \\
\text { piezoelectric polymers }\end{array}$ & Yes & $\begin{array}{c}11,185- \\
187,237,238,3 \\
71,372]\end{array}$ \\
\hline Surface tension & Heat & $\begin{array}{c}\text { Solder, tin, } \\
\text { polymers, etc. }\end{array}$ & $\mathrm{nm}-\mathrm{mm}$ & $\begin{array}{l}\text { Hinges can be sealed } \\
\text { (locked) after folding }\end{array}$ & $\begin{array}{l}\text { Elevated temperature } \\
\text { to melt metals }\end{array}$ & No & {$[36,271]$} \\
\hline Magnetism & $\begin{array}{l}\text { Magnetic } \\
\text { fields }\end{array}$ & $\begin{array}{l}\text { Ferromagnetic } \\
\text { materials }\end{array}$ & $\mathrm{nm}-\mathrm{mm}$ & $\begin{array}{l}\text { Remote control by } \\
\text { magnetic field }\end{array}$ & $\begin{array}{l}\text { Locking mechanism } \\
\text { required to keep it in } \\
\text { position }\end{array}$ & Yes & [181,373-377] \\
\hline \multirow[t]{3}{*}{ Shape memory } & Heat & $\begin{array}{l}\text { Shape memory } \\
\text { polymers }\end{array}$ & $\mu \mathrm{m}-\mathrm{mm}$ & $\begin{array}{l}\text { Simple thermal } \\
\text { actuation }\end{array}$ & $\begin{array}{c}\text { Programming required } \\
\text { for SMPs or heat must } \\
\text { be delivered locally }\end{array}$ & No & $\begin{array}{c}{[287,254,281} \\
282]\end{array}$ \\
\hline & $\begin{array}{l}\text { Light to } \\
\text { induce } \\
\text { molecular } \\
\text { changes }\end{array}$ & $\begin{array}{l}\text { Liquid-crystal } \\
\text { elastomers and } \\
\text { gels or } \\
\text { photosensitive } \\
\text { polymers } \\
\end{array}$ & $\mu \mathrm{m}-\mathrm{mm}$ & $\begin{array}{l}\text { Remote; room } \\
\text { temperature }\end{array}$ & $\begin{array}{l}\text { Usually requires UV } \\
\text { light }\end{array}$ & Yes & $\begin{array}{l}{[168,291,205,} \\
219,220,378- \\
380]\end{array}$ \\
\hline & $\begin{array}{l}\text { Light to } \\
\text { deliver heat }\end{array}$ & $\begin{array}{c}\text { Pre-strained } \\
\text { shrink films }\end{array}$ & $\mu \mathrm{m}-\mathrm{cm}$ & $\begin{array}{c}\text { Simple printing } \\
\text { approach }\end{array}$ & $\begin{array}{c}\text { Unproven at small } \\
\text { length scales }\end{array}$ & $\mathrm{No}^{\text {a) }}$ & {$[254,324,269]$} \\
\hline Shrinkage & Heat & Polyimide (PI) & $\mu \mathrm{m}$ & $\begin{array}{c}\text { Different angle } \\
\text { displacement can be } \\
\text { achieved depending on } \\
\text { curing temperature }\end{array}$ & $\begin{array}{c}\text { High temperature } \\
\text { needed }\left(250 \sim 500{ }^{\circ} \mathrm{C}\right) \\
\text { pattern PI hinge }\end{array}$ & $\mathrm{No}^{b)}$ & {$[267,268]$} \\
\hline
\end{tabular}

a) also includes approach as described in Figure 25 .

b) but can dynamically control angle by heating due to thermal expansion of polyimide [267] 